\title{
Article
}

\section{Loss of Individual Mitochondrial Ribonuclease P Complex Proteins Differentially Affects Mitochondrial tRNA Processing In Vivo}

\author{
Maithili Saoji ${ }^{1,2,3}$, Aditya Sen ${ }^{1,2}$ and Rachel T. Cox ${ }^{1, *(1)}$ \\ 1 Department of Biochemistry and Molecular Biology, Uniformed Services University, \\ Bethesda, MD 20814, USA; maithilisaoji@gmail.com (M.S.); Aditya.sen@usuhs.edu (A.S.) \\ 2 Henry M. Jackson Foundation, Bethesda, MD 20817, USA \\ 3 Alector Inc., 131 Oyster Point Blvd, San Francisco, CA 94080, USA \\ * Correspondence: rachel.cox@usuhs.edu
}

Citation: Saoji, M.; Sen, A.; Cox, R.T. Loss of Individual Mitochondrial Ribonuclease P Complex Proteins Differentially Affects Mitochondrial tRNA Processing In Vivo. Int. J. Mol. Sci. 2021, 22, 6066. https://doi.org/ $10.3390 /$ ijms 22116066

Academic Editor:

Alessandra Ferramosca

Received: 7 May 2021

Accepted: 2 June 2021

Published: 4 June 2021

Publisher's Note: MDPI stays neutral with regard to jurisdictional claims in published maps and institutional affiliations.

Copyright: (c) 2021 by the authors. Licensee MDPI, Basel, Switzerland. This article is an open access article distributed under the terms and conditions of the Creative Commons Attribution (CC BY) license (https:// creativecommons.org/licenses/by/ $4.0 /)$.

\begin{abstract}
Over a thousand nucleus-encoded mitochondrial proteins are imported from the cytoplasm; however, mitochondrial (mt) DNA encodes for a small number of critical proteins and the entire suite of mt:tRNAs responsible for translating these proteins. Mitochondrial RNase P (mtRNase P) is a three-protein complex responsible for cleaving and processing the $5^{\prime}$-end of mt:tRNAs. Mutations in any of the three proteins can cause mitochondrial disease, as well as mutations in mitochondrial DNA. Great strides have been made in understanding the enzymology of mtRNase P; however, how the loss of each protein causes mitochondrial dysfunction and abnormal mt:tRNA processing in vivo has not been examined in detail. Here, we used Drosophila genetics to selectively remove each member of the complex in order to assess their specific contributions to mt:tRNA cleavage. Using this powerful model, we find differential effects on cleavage depending on which complex member is lost and which mt:tRNA is being processed. These data revealed in vivo subtleties of mtRNase $\mathrm{P}$ function that could improve understanding of human diseases.
\end{abstract}

Keywords: mtRNase P; mitochondria; tRNA; Drosophila; mtDNA

\section{Introduction}

The mitochondrial genome in metazoans is highly conserved, encoding the same 13 oxidative phosphorylation proteins, 2 ribosomal RNAs (mt:rRNA), and a complete set of 22 transfer RNAs (mt:tRNAs) required for translation [1]. Similar to its bacterial ancestor, mitochondrial DNA is transcribed as polycistronic RNA, which is cleaved into individual products post-transcriptionally [2]. In the metazoan mitochondrial genome, mRNAs and rRNAs are interspersed by tRNAs, an organization that is commonly referred to as the tRNA punctuation model [3]. With this arrangement, correctly processed mt:tRNAs release the other mtRNA products through the action of mitochondrial $(\mathrm{mt})$ RNase $\mathrm{P}$ and RNase Z (ELAC2) acting at mt:tRNA $5^{\prime}$ - and $3^{\prime}$-ends, respectively [4,5].

In the nucleus, canonical RNase $\mathrm{P}$ is a ribonucleoprotein with a catalytically active $\mathrm{H} 1$ RNA responsible for cleaving the $5^{\prime}$ leader sequence from precursor tRNAs to generate tRNAs with mature $5^{\prime}$-ends [6,7]. In contrast, in mitochondria, human mtRNase P carries out this function. $\mathrm{mtRNase} P$ is a three-protein complex comprised of mitochondrial ribonuclease $P$ proteins (MRPP) 1, 2, and 3 (Figure 1A) [4]. MRPP1 (TRMT10C) is a methyltransferase that catalyzes the $\mathrm{N}^{1}$ methylation of adenosine or guanosine at the nineth position of 19 out of 22 human mt:tRNA [8,9]. MRPP2 (HSD17B10/SDR5C1) is a multifunctional protein of the small chain dehydrogenase reductase (SDR) family of proteins involved in amino acid catabolism and lipid metabolism [10,11]. MRPP3, a homolog of the single subunit PRORPs present in the nucleus and organelles of land plants, is the catalytic metallo-endonuclease that cleaves mt:tRNAs at the $5^{\prime}$-end [4,12-14]. MRPP1 and MRPP2 form a tight subcomplex 
which is required for the methyltransferase activity and stability of MRPP1 but not for the dehydrogenase activity of MRPP2 $[4,9,15]$. Methylation of mt:tRNAs by the subcomplex is not a prerequisite for the endonuclease activity of MRPP3 [9]. In vitro reconstitution experiments indicate that the MRPP1/2 subcomplex may function as a so-called "maturation platform" by enhancing the $3^{\prime}$-end cleavage efficiency of RNase $Z$ and $3^{\prime}$-CCA addition [16]. For $5^{\prime}$-end processing, the MRPP1/2 subcomplex is thought to act as a scaffold and is obligatory for the catalytic activity of MRPP3 perhaps by enhancing $\mathrm{Mg}^{2+}$ binding and/or stabilizing the active site conformation of the endonuclease $[4,9,16]$. In addition, recent findings suggest that MRPP1/2 increases the affinity of MRPP3 for its pre-tRNA substrate and that the presence of MRPP3 can enhance the methylation activity of MRPP1/2 [17]. There is increasing evidence that $5^{\prime}$-end mt:tRNAs are not processed uniformly in vitro and in vivo by $\mathrm{mtRNase} P$, which suggests that there are as yet unidentified additional factors or mechanisms that aid cleavage $[18,19]$.

Defective mt:tRNA processing is associated with mitochondrial diseases in humans (reviewed in [20]). These diseases can be due to mutations in the mt:tRNA or in the proteins involved in mt:tRNA processing and maturation. There are approximately 275 known disease-associated mutations in mt:tRNAs, most of which are present outside the anticodon region [21]. Point mutations affecting the $5^{\prime}$ - and $3^{\prime}$-end processing of mt:tRNAs are associated with maternally inherited hypertension, cardiomyopathies, ophthalmoplegia, and mitochondrial encephalomyopathy with lactic acidosis and stroke-like episodes (MELAS), to name a few $[20,21]$. Interestingly, different mutations in the same mt:tRNA often manifest diverse clinical symptoms, and there are no cures for these diseases. Mutations in the $\mathrm{mtR}$ Nase $\mathrm{P}$ complex and RNase $\mathrm{Z}$ are linked to severe, sometimes fatal mitochondrial diseases. MRPP2 has the highest number of identified mutations that cause HSD10 disease [22]. HSD10 patients experience a variable age of onset and severity of the disease depending on the mutation. The patients display an array of classic multisystemic mitochondrial disease symptoms such as loss of cognitive and motor function, epilepsy, blindness, cardiomyopathy, and neurodegeneration [22]. Data collected from patient fibroblasts and in vitro experiments have shown that pathogenic mutations in MRPP2 affect tetramerization and dehydrogenase and/or mtRNase P activity [23-25]. Patients identified with pathogenic mutations in MRPP1 suffer from lactic acidosis, hypotonia, feeding difficulties, and deafness, and die as infants [26]. These patient fibroblasts showed an increased accumulation of unprocessed precursor mt:tRNAs but the methyl transferase activity was normal suggesting the in vivo role of MRPP1 in mtRNase P function is primarily responsible for the disease symptoms rather than its methyltransferase activity. A preprint has identified a mutation in MRPP3 that causes Perrault syndrome, a syndrome leading to neurological symptoms, deafness and primary ovarian insufficiency often caused by mutations in multiple proteins involved in mtDNA transcription and translation [27]. These patients apparently also accumulate unprocessed mtRNAs. In addition to patient data, there are mouse models that have been used to study the effects of loss of mtRNase P function. Mouse full-body knockouts of MRPP2 and MRPP3 are embryonic lethal [19,28]. Conditional knockouts of MRPP3 in heart and skeletal muscle lead to lethality at 11 weeks with the mice exhibiting cardiomyopathy and muscle defects [19]. The affected tissues showed increased accumulation of unprocessed RNA transcript, defective transcription, translation and mitoribosomal assembly. Mouse conditional knockout of MRPP2 in endothelial cells and immune cells showed lethality by 25 and 26 weeks, respectively, and had mitochondrial defects [28].

Since mitochondrial disease presentation is complex and multisystemic, model systems are a useful tool to dissect the in vivo role of MRPP1, 2, and 3 in mt:tRNA processing during development. We previously identified the Drosophila homologs of MRPP1 (Roswell (Rswl)) and MRPP2 (Scully (Scu)) and MRPP3 (Mulder (Mldr)) (Figure 1A) [29]. In Drosophila, all three proteins associate with each other and localize to mitochondria [29]. 
A

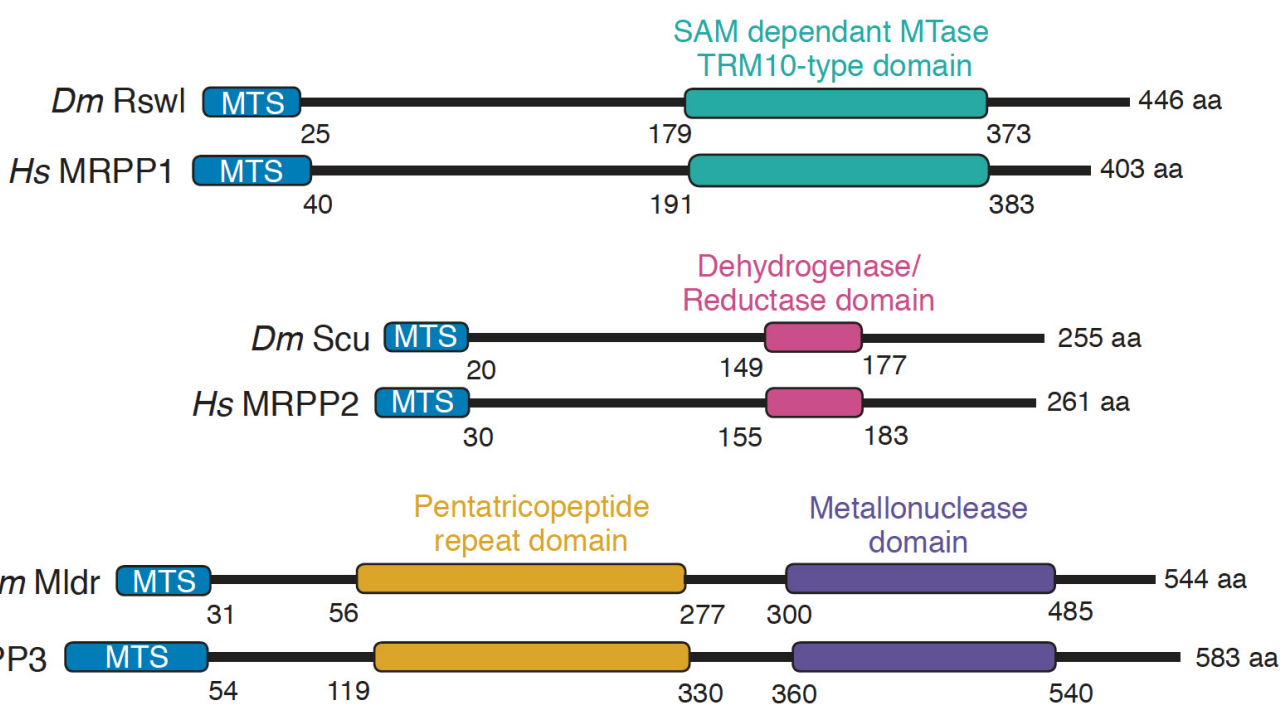

B

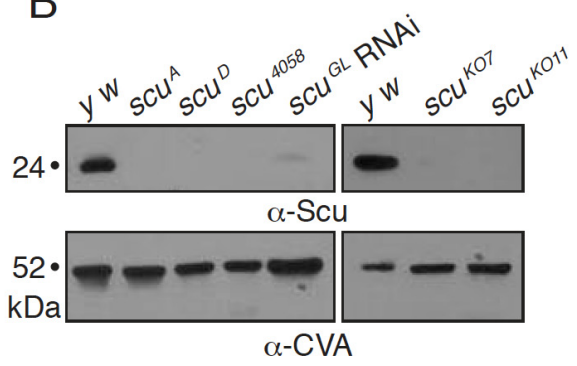

C

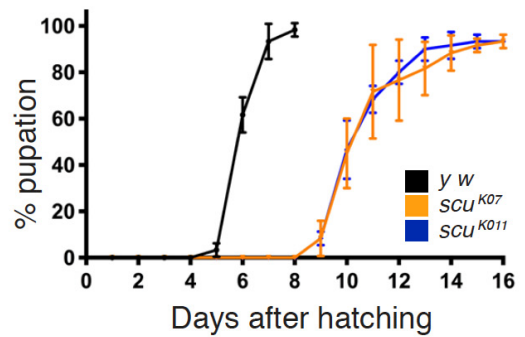

D
E

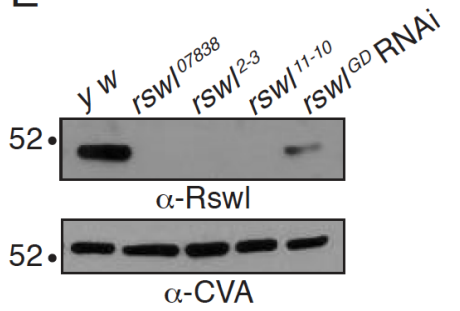

F

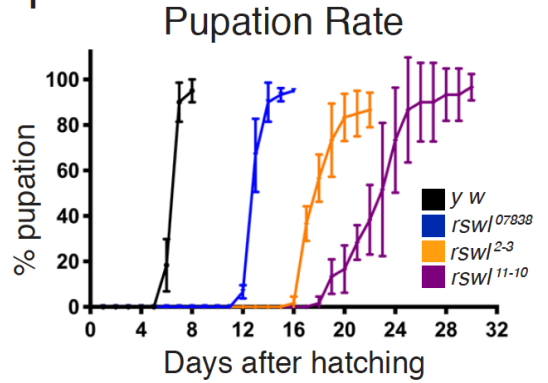

G

\begin{tabular}{ccc} 
& \% pupation* & \% eclosion \\
\hline$y w$ & $95 \pm 5$ & $85 \pm 10$ \\
$r s w l^{07838}$ & $95 \pm 0$ & 0 \\
$r s w l^{2-3}$ & $86.6 \pm 7.6$ & 0 \\
$r s w l^{11-10}$ & $96.6 \pm 5.7$ & 0 \\
\hline${ }^{*} \pm$ s.d. & &
\end{tabular}

Figure 1. Loss of function alleles of $r s w l$ and $s c u$ cause lethality in flies. (A) Schematic showing the domain structure of Roswell, Scully, and Mulder and their homology in humans. The mitochondrial targeting sequence (MTS, blue) was predicted using MitoProt server, and the domain boundaries were predicted using Clustal Omega based on human homologs [30,31]. MTase: methyltransferase. (B-D) CRISPR/Cas9 induced loss of scu caused lethality. (B) Antibodies raised against Scu indicate all five $s c u$ alleles appear protein null via Western blot compared to the wild-type (y w), including ubiquitous $s c u^{G L}$ RNAi expression. (C,D) $s c u^{K O 7}$ and $s c u^{K O 11}$ had delayed pupation (C) and failed to eclose (D) at room temperature. (E-G) The three $r s w l$ alleles did not have detectable protein on Western blot. Ubiquitous $r s w l^{G D}$ RNAi expression shows reduced protein levels (E). (F) rswl mutant larvae eventually pupate but had delayed development, and none enclosed at room temperature (G). CVA: anti-ATP synthase. s.d. was calculated using GraphPad PRISM (C,D,F,G).

Mutations in scu and mldr and constitutive knockdown of $r s w l, s c u$, and mldr lead to delayed pupation and pupal lethality. The mutant larvae had defective mitochondria, marked by the loss of outer mitochondrial membrane permeability and reduced ATP levels [29]. mldr and scu mutants and rswl RNA interference (RNAi) showed an accumulation of precursor RNA transcripts on Northern blots probed with tRNAs located in different positional contexts within polycistronic transcripts [29]. Finally, we showed that 
overexpression of Rswl and Mldr caused lethality in flies and flies overexpressing Mldr, but not Rswl or Scu, had associated mitochondrial morphology defects [29].

In the current study, we identified null alleles of $r s w l$ and $s c u$ and used qPCR to examine how the loss of individual complex members affects mt:tRNA junction processing. We first develop CRISPR/Cas9 knockouts of $r s w l$ and $s c u . r s w l^{2-3}, r s w l^{11-10}$ and the previously uncharacterized P-element insertion mutation $r s w l^{07838}$, all showed delayed development and pupal lethality. $s u^{K O 7}$ and $s c u^{K O 11}$ are also developmentally delayed and pupal lethal. These $r s w l$ and $s c u$ mutants were associated with mitochondrial morphology defects and reduced ATP production. Lastly, we examined mt:tRNA 5-' and $3^{\prime}$-end processing of specific junctions located in different polycistronic transcript contexts in the absence of each protein. Overall, our qPCR data suggests that mutations in different mtRNase $P$ complex members differentially affect junction processing for different mt:tRNA junctions. Loss of Rswl consistently had the greatest effect, and loss of Scu did not always affect junction processing depending on the mt:tRNA. Using the Drosophila model, this is the first time loss of all three mtRNase P members has been examined simultaneously in vivo for their effect on junction specific mtRNA processing.

\section{Results}

\subsection{Protein Null Alleles of Scully and Roswell Confer Lethality and Mitochondrial Damage}

We previously characterized loss of mtRNAse $\mathrm{P}$ and found the mutant flies are pupal lethal, have reduced ATP, and accumulate longer, unprocessed mtRNA [29]. However, the $s c u$ alleles $\left(s c u^{A}\right.$ and $\left.s c u^{D}\right)$ are ethyl methanesulfonate (EMS) induced mutations, and the rswl mutant phenotype was produced by a single available RNAi knockdown strain. In addition, the Northern blot analysis indicated larger unprocessed mtRNAs species but did not analyze specific mt:tRNA junction processing. To generate better genetic tools for rswl and scu, we used CRISPR/Cas9 to create knockout alleles and generated antibodies against both proteins to determine protein levels in the mutants. scu knockouts were made by crossing transgenic flies stably expressing a single guide RNA complementary to the $5^{\prime}$-end of the protein-coding region with a transgenic fly line stably expressing Cas9 in the germline under control of a germline-specific promoter nosGAL4 [32,33]. Two knockout alleles, $s c u^{K O 7}$ and $s c u^{K O 11}$, were randomly selected from a pool of 10 positives. Sequencing of $s c u^{K O 7}$ and $s c u^{K O 11}$ confirmed the expected edit by the guide RNA, which was repaired by non-homologous end joining (NHEJ), leading to a frameshift mutation at amino acid position 9 and 10 in the mitochondrial targeting sequence and a premature stop codon at amino acid positions 74 and 29, respectively (Figure S1A). To confirm these alleles are protein nulls, we generated antibodies to $\mathrm{Scu} . \mathrm{scu}^{\mathrm{KO}}$ and $s c u^{K O 11}$, as well as $s c u^{A}$ and $s c u^{D}$, did not have detectable protein on Western blot and have reduced transcripts (Figure $1 \mathrm{~B}$ and Figure S2A). Antibodies raised against Scu colocalize with ATP synthase in Drosophila ovarian follicles using indirect immunofluorescence imaging (Figure S3). Using Western blots, antibodies raised against Scu also recognized an appropriately sized band in mitochondrial extract derived from adult flies (Figure S3). Both CRISPR/Cas9 induced null alleles caused a developmental delay in pupation and a failure to eclose into adults (Figure 1C,D). In addition, larvae had reduced ATP and mitochondria with mitochondrial morphological defects, indicative of mitochondrial dysfunction (Figure 2A-C,G) [34,35]. This agrees with our previous characterization of three other alleles of $s c u$ : $s c u^{D}$ (S163F, point mutation in a conserved residue), $s c u^{A}$ (Q159Stop, point mutation resulting in a C-terminal truncation), and $s c u^{4058}$ (frameshift at E205, leading to a stop codon 20 aa downstream) [29].

Our previous work showed ubiquitous rswl RNAi expression caused lethality, low ATP levels, and an accumulation of larger mtRNA species [29]. While consistent with our other data on mldr and scu mutants, we could not be sure the phenotype reflected a true loss-of-function mutant phenotype as it only represented one RNAi line, and we did not have an Rswl antibody. In addition, unlike $m l d r$ and $s c u$, this knockdown did not show mitochondrial morphological defects. Thus, we used CRISPR/Cas9 to generate a mutant allele. While we used two guide RNAs injected into embryos, sequence confirmation of 
the positive clones revealed that both alleles, $r s w l^{2-3}$ and $r s w l^{11-10}$, were created by NHEJ of the Cas9 cleavage by only the guide RNA directed to the $3^{\prime}$-end of the coding region. This NHEJ leads to eight and eleven nucleotide deletions, respectively, and frameshift mutations in the $\mathrm{C}$ terminal extension (Figure S1B). To determine the effect of these alleles on the amount of available protein, we generated Rswl antibodies. Antibodies raised against Rswl colocalize with antibodies to ATP synthase in Drosophila ovarian follicles using indirect immunofluorescence imaging (Figure S3). This colocalization was not as strong compared to Scu (Figure S3). Since Scu is a homotetramer, this may be because there is a higher abundance of the Scu protein compared to Rswl, or it could be due to the anti-Rswl antibody not being as efficient as the Scu antibody for immunofluorescence. Using Western blots, antibodies raised against Rswl also recognize an appropriately sized band in mitochondrial extract derived from adult flies (Figure S3). Both rswl mutations result in protein nulls as judged by Western blot (Figure 1E), and the resulting transcripts were reduced (Figure S2B). A third allele, $r s w l^{07838}$, caused by a transposable element inserted into the first intron, also appeared protein null and had reduced transcript levels (Figure 1E and Figure S2B). In contrast, the previously characterized RNAi line has residual protein (Figure 1E). $r s w l^{2-3}$ and $r s w l^{11-10}$ delayed pupation (Figure 1F). All three $r s w l$ mutants failed to enclose and had reduced levels of ATP, similar to our previous result with rswl RNAi (Figures 1G and 2H) [29]. Finally, in contrast to our initial observation of $r s w l$ RNAi, all three alleles caused mitochondrial swelling in larval neuroblasts (Figure 2D-F).
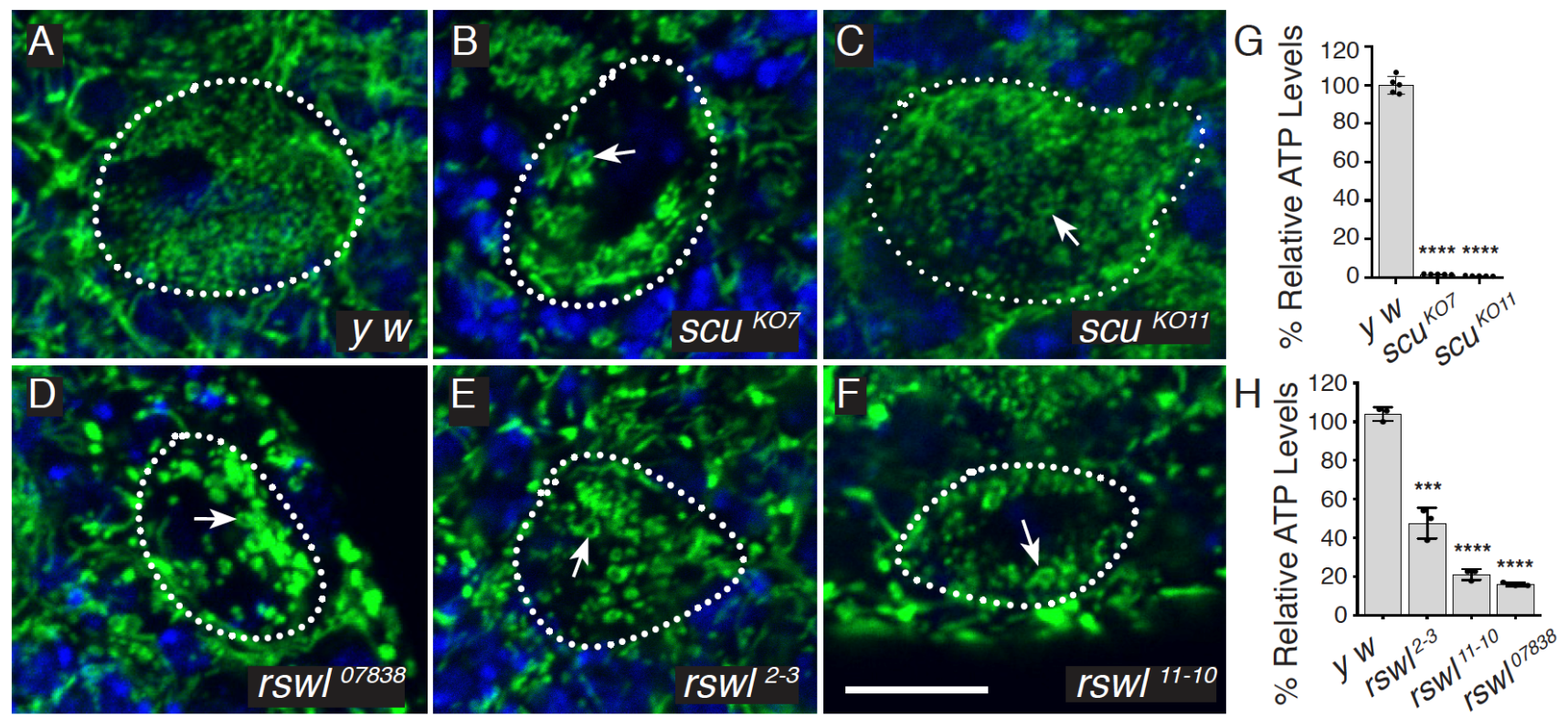

Figure 2. Loss of function of $r s w l$ and $s c u$ are associated with mitochondrial defects. (A-F) Neuroblast (NB) stem cells (dotted outlines) from larval brains labeled for mitochondria (green) and DAPI (blue). Neuroblasts in wild-type (y w) brains had small, dispersed mitochondria (A). In contrast, mitochondria in the neuroblasts of $r s w l$ and scu mutants (B-F) were swollen and ring-shaped (arrows). Number of NB with swollen mitochondria =1/56 (A), 71/80 (B), 29/30 (C), 19/19 (D), 15/17 (E), and 22/25 (F). (G,H) Total relative ATP levels were reduced in scu (G) and rswl (H) mutant larvae. Green: anti-ATP synthase; blue: DAPI. Scale bar: $10 \mathrm{~mm}$ in F for A-F. Error bars: S.E.M. calculated using GraphPad PRISM using an unpaired $t$-test, two-tailed. $(\mathbf{G}, \mathbf{H}){ }^{* * * *} p<0.0001 ;{ }^{* * *} p<0.001$.

\subsection{Loss of mtRNase P Complex Members Differentially Affects mt:tRNA 5'-End Processing In Vivo}

Drosophila mtDNA is transcribed as five polycistronic transcripts compared to three for human mtDNA (Figure 3A,B) [36-38]. Both mtDNAs encode for the same products. In the polycistronic transcripts, mt:tRNA $5^{\prime}$-ends were found in different RNA contexts (i.e., next to rRNA, mRNA, tRNA, or non-coding RNA) (Figure 3A,B). It is possible the RNA 
environment could affect how $\mathrm{mtRNase} P$ recognizes cleavage sites. To analyze how the loss of any of the three mtRNase P components (Mldr, Rswl, and Scu) affects the processing of different mt:tRNA junctions, we collected first instar larval mutant extract and used qPCR to analyze mt:tRNA junction processing. Scu, Rswl, and Mldr are maternally loaded; thus, there is wild-type protein available early on in zygotically mutant embryos (Figure S4). However, Western blots probing extract isolated from mutant first instar larvae did not have detectable protein (Figure 1). In addition, we noticed that the mutant larvae appeared to grow somewhat asynchronously at later stages, particularly for the rswl mutants, and we wanted to ensure all the samples were taken at the same age. Therefore, we used an extract from first instar larvae for our analysis. qPCR was performed using primers that amplify directly across the junctions resulting in approximately 100-nucleotide products (Table S1). The PCR product amount was normalized within each sample against 18S RNA. To compare the amount of junction cleavage between genotypes, each junction reaction was compared to wild-type. If cleavage occurred at a normal rate, the mutant value would not be statistically different from the wild-type for a given set of primer pairs. Data are represented as fold changes on a $\log _{2}$ scale.

We first examined $5^{\prime}$-end $\mathrm{mt}$ :tRNA junction processing for mt:tRNAs located adjacent to four different mtRNAs: non-coding (nc) mtRNA, mt:rRNA, mt:mRNA, and mt:tRNA. Three of the tested junctions have analogous junctions in human mtDNA (Figure 3B, pink, blue and yellow triangles), and the fourth is shown in a similar context (Figure 3B, green triangle). The prediction was that abolishing any mtRNase P complex member should result in decreased mt:tRNA $5^{\prime}$-end processing, and reduction of the $3^{\prime}$-end mt:tRNA processing enzyme RNase $Z$ should have no effect. Two $\mathrm{mt}$ :tRNAs supported this prediction with qPCR. mt:tRNA ${ }^{\text {Met }}$ is downstream of nc mtRNA, and mutations in scu, rswl, and mldr caused a significant increase in the amount of unprocessed junction relative to wild-type (Figure 3C, pink triangle). We also examined the loss of RNase $\mathrm{Z}$ using the upstream activating sequence (UAS)/galactose metabolism (GAL)4 conditional expression system. Expressing UAS-dRNaseZ GD10927 (RNase Z RNAi) ubiquitously using daughterless GAL4 (daGAL4) resulted in a reduced RNase $Z$ transcript (Figure S2D). In addition, knocking down RNase $Z$ ubiquitously results in no pupation, as shown previously, with larvae only reaching second instar [39]. RNase Z RNAi has no effect on mt:tRNA ${ }^{\text {Met }} 5^{\prime}$ end processing (Figure 3C). mt:tRNA ${ }^{\mathrm{Leu}(\mathrm{CUN})}$, which is directly downstream of $\mathrm{mt}: 16 \mathrm{~S}$ rRNA, has a similar pattern of unprocessed mt:tRNA (Figure 3D, yellow triangle). We also examined mt:tRNA ${ }^{\text {Gly }}$, which is adjacent to 18 non-coding nucleotides downstream of cytochrome c oxidase subunit III (COIII) (Figure 3E). Loss of both $r s w l$ alleles accumulated significantly more unprocessed junctions. In contrast, loss of $m l d r$ and $s c u$ null alleles did not. The final mt:tRNA $5^{\prime}$-end junction we tested, mt:tRNA ${ }^{\text {Asn }}$, was found in a cluster of five mt:tRNAs, and the $3^{\prime}$-end cleavage site of adjacent mt:tRNA ${ }^{A r g}$ was the $5^{\prime}$-end cleavage site of mt:tRNA ${ }^{\text {Asn }}$ (Figure 3F). For the $5^{\prime}$-end of mt:tRNA ${ }^{\text {Asn }}$, only the loss of one $r s w l$ null allele caused an accumulation of unprocessed junction. Loss of RNase $Z$ also accumulated unprocessed junctions (Figure 3F).

\section{3. mt:tRNA 3'-End and Non-Canonical Junction Processing Is Affected Differentially by Loss of $m t R$ Nase P Complex Members}

mt:tRNA $3^{\prime}$-end processing iwass achieved through the enzymatic activity of RNase Z/ELAC2. Data from cultured cells have shown that mt:tRNAs located on the heavy and light strands of human mtDNA have differential requirements for RNase Z/ELAC2 [40]. In addition, mouse tissues lacking MRPP3 appear to exhibit hierarchical processing for certain junctions where mt:tRNA $5^{\prime}$-ends must be cleaved before $3^{\prime}$-end processing can take place [19]. To determine the in vivo effect of loss of each RNase P complex member on $3^{\prime}$-end processing, we performed the same qPCR analysis on two mt:tRNA junctions (Figure $4 \mathrm{~A}$, triangles). mt:tRNA ${ }^{\text {Ile }} 3^{\prime}$-end is adjacent to nc mtRNA and is in an analogous position to human mt:tRNA ${ }^{\text {Pro }}$. Loss of all mtRNase $P$ components caused an accumulation of unprocessed junction consistent with previous data (Figure 4B) [19]. The second junction 
we tested was the $3^{\prime}$-end of mt:tRNA ${ }^{\text {Leu(CUN) }}$, which is 10 nucleotides upstream of ND1 and is in an analogous position to human mt:tRNA ${ }^{\text {Leu(UUR). In contrast to mt:tRNA }}{ }^{\text {Ile }}$, loss of $r s w l$ and $m l d r$ resulted in accumulation of product, but the loss of $s c u$ did not.

In humans, all but two mtDNA products are flanked on at least one side by mt:tRNA. Thus, cleavage of mt:tRNA by mtRNase P ( $5^{\prime}$-end) or RNase Z/ELAC2 ( $3^{\prime}$-end) could conceivably initiate or complete processing of at least one end of most mtRNA products. However, there are certain non-canonical junctions in mtRNA that are not adjacent to mt:tRNA. How these junctions are cleaved is not completely understood. In Drosophila, we tested four out of the five non-canonical junctions (Figure 4A, triangles). We examined two junctions with all mutants (Figure $4 \mathrm{D}, \mathrm{E}$ ) and two more with a subset of mutants (Figure 4F,G). nc RNA-ND6 and nc RNA-cytochrome c oxidase subunit I (COI) are in a similar RNA context because while the upstream sequence is non-coding, it is mirror sequence for mt:tRNA ${ }^{\text {Pro }}$ and mt:tRNA ${ }^{\mathrm{Tyr}}$, respectively, encoded on the opposite strand (Figure $4 \mathrm{D}, \mathrm{E}$, blue circles) [41]. Thus, the secondary structure derived from the mirror mt:tRNA could render positional information to the enzyme. Despite this similarity, a loss of mtRNase $P$ had no effect on junction processing of nc RNA-ND6, but a loss of mtRNase P for all three proteins caused junction accumulation of nc RNA-COI (Figure 4D,E). While not all mutants were tested for ND6-cytochrome b (Cytb) and nc RNA-ND4L, these junctions also showed differential sensitivity (Figure $4 \mathrm{~F}, \mathrm{G}$ ). Loss of $s c u$ and $r s w l$ had no effect on junction processing for ND6-Cytb. Only the loss of rswl led to an accumulation of unprocessed junction of nc RNA-ND4L. These data support that mtRNase $P$ is required for certain non-canonical junction processing, but in Drosophila, this requirement was not equal for all mtRNase P subunits.

\subsection{Loss of RNase P Differentially Affects the Abundance of Individual Transcripts Derived from} the Same Polycistronic Transcript

In humans, deep sequencing has shown mtRNA levels vary even though they are located within the same polycistronic transcript [42]. In mice, mt:rRNAs and mt:mRNAs located on the heavy strand are differentially affected with loss of LRPPRC, a pentatricopeptide repeat (PPR) containing protein that regulates mtRNA stability [43]. mt:mRNAs are reduced in LRPPRC knockout mouse tissues, whereas the mt:rRNAs and the intervening mt:tRNA ${ }^{\text {Val }}$ are increased. We wanted to know if transcript abundance in the mtRNase $P$ mutant background could potentially explain the increase in unprocessed junctions. Therefore, we measured four different transcripts in the same polycistronic transcript using qPCR from all of the mutants analyzed (Figure 5A, asterisks). The primers used spanned the single mtRNA, and thus, this analysis did not reflect whether the single mtRNA was present in a larger transcript. We found that mt:tRNA ${ }^{\text {Met }}$ levels in mtRNase P mutant backgrounds were not substantially increased compared to wild-type ( $y$ w) (Figure 5B) even though the mutants accumulated unprocessed junction (Figure 3C). mt:tRNA ${ }^{\text {Asn }}$ transcript levels were decreased in some mutant backgrounds and similar to wild-type in others (Figure 5C) while only the loss of $r s w l$ and RNase $\mathrm{Z}$ accumulated unprocessed junction (Figure 3F). We also measured ND2 and COIII using qPCR. These transcript levels were differentially affected by the genetic background, with loss of mtRNase P and RNase $\mathrm{Z}$ causing an accumulation of ND2 whereas COIII levels were reduced or unaffected (Figure 5D,E). Similarly, mt:tRNA ${ }^{\text {Asn }}$ and COIII transcripts showed no increases in the mutant backgrounds compared to wild-type as analyzed by Northern dot blots (Figure S5). 
A

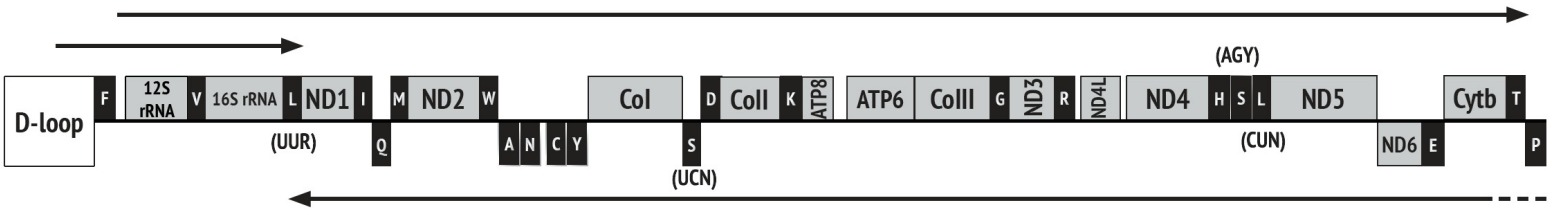

B
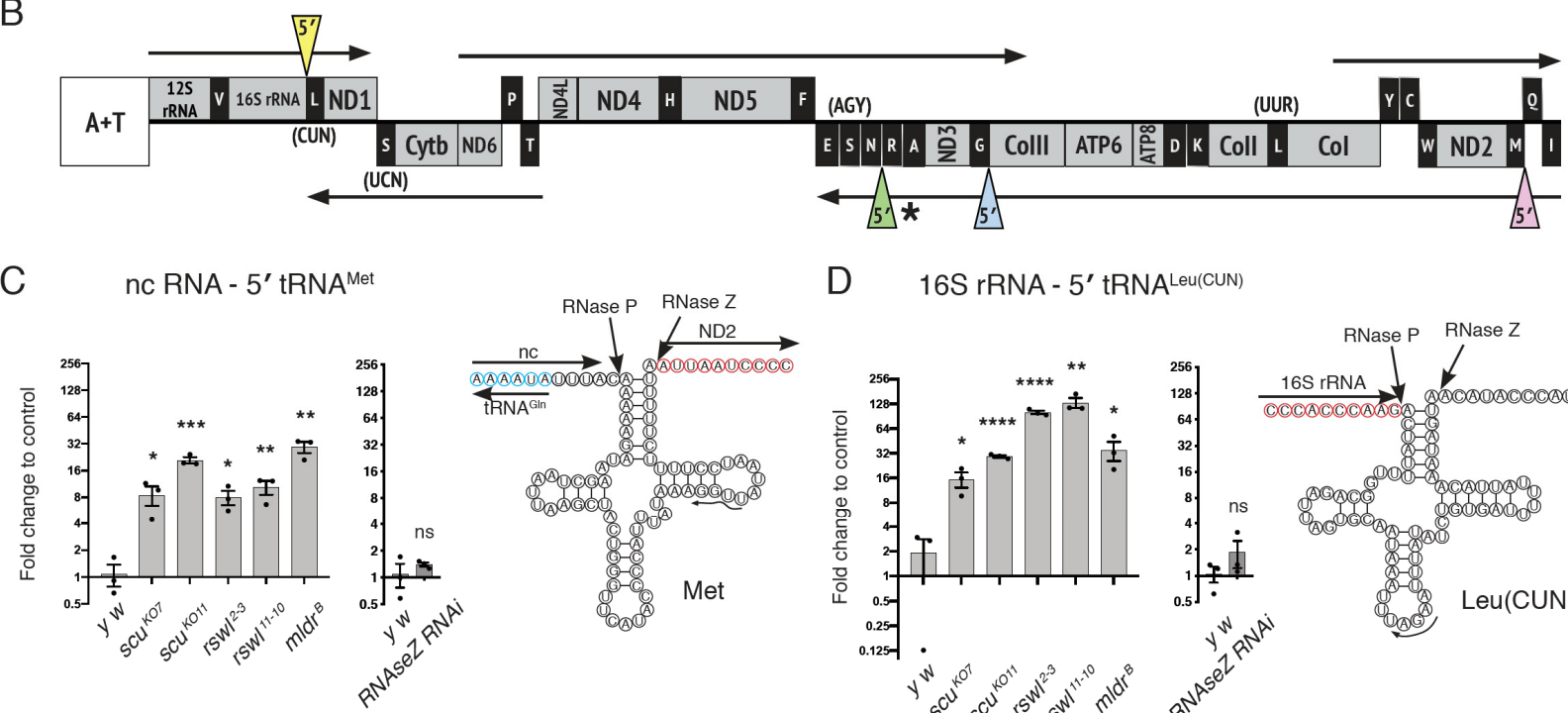

D $16 S$ rRNA - 5' tRNA ${ }^{\text {Leu(CuN) }}$

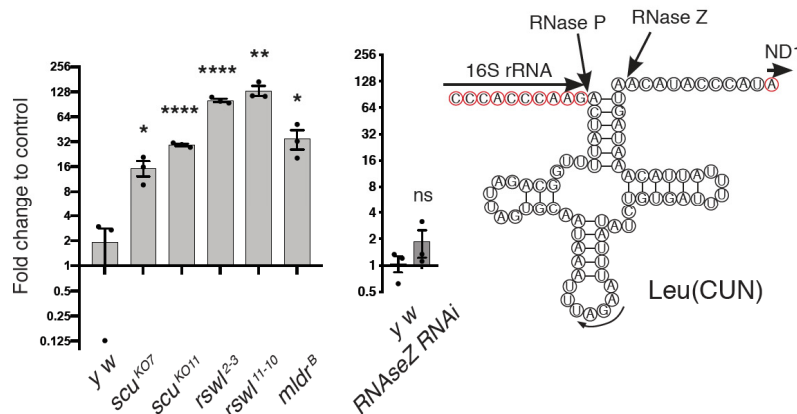

E

COIII - 5' tRNA Gly

$\mathrm{F}$

3' tRNA ${ }^{\text {Arg }}$ - 5' tRNA ${ }^{\text {Asn }}$
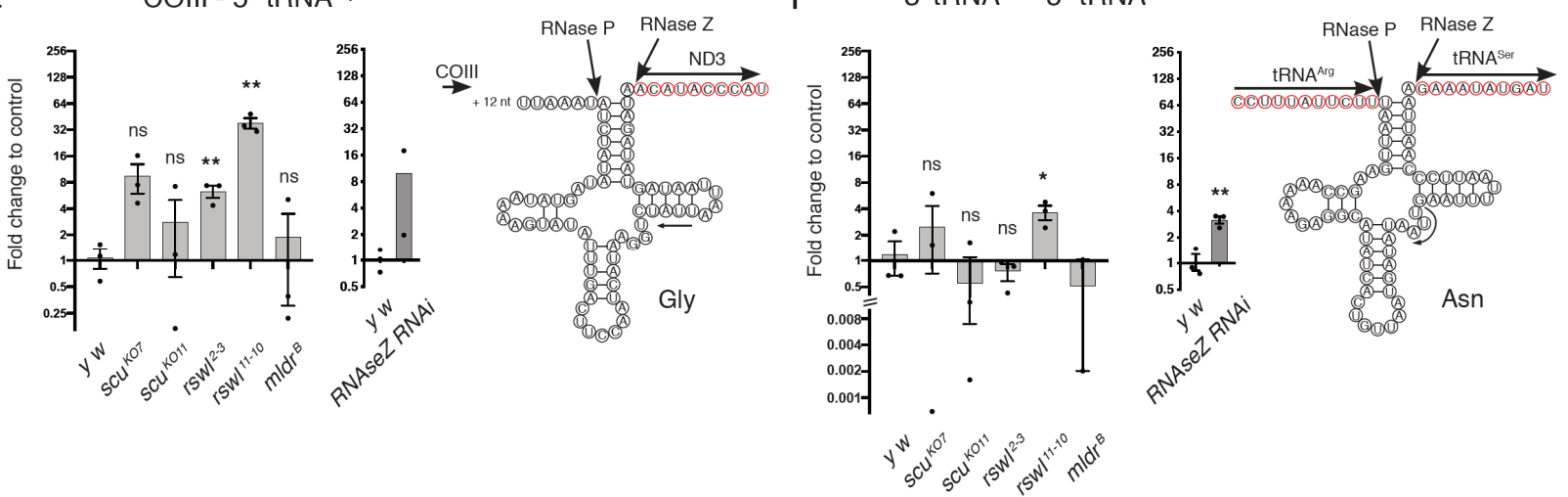

Figure 3. Mutations in mtRNase P complex proteins differentially affect mt:tRNA $5^{\prime}$-end processing. (A,B) Linear schematic of human (A) and Drosophila (B) circular mtDNA. Protein coding regions (mRNA) and ribosomal RNA (rRNA) are depicted in grey, whereas mt:tRNAs are in black. Both mtDNAs encode the same products in a slightly different order. Arrows indicate polycistronic transcripts, with humans containing three and Drosophila, five. The non-coding regions that control replication (human and Drosophila) and transcription (human) are the displacement (D) loop and the A+T region that is rich in adenine and thymine. The mt:tRNA $5^{\prime}$-ends tested are indicated with colored triangles (B). The asterisk indicates a junction that could also be recognized and cleaved at the mt:tRNA $3^{\prime}$-end. (C-F) Graphs representing the $\log _{2}$ fold change in qPCR levels and the corresponding predicted mt:tRNA cloverleaf structure for mt:tRNA $5^{\prime}$-end canonical junctions between (C, pink triangle) non-coding (nc) RNA: $5^{\prime}$ tRNA ${ }^{\text {Met }}$; (D, yellow triangle) 16S rRNA: $5^{\prime}$ tRNA ${ }^{\text {Leu(CUN) }}$; (E, blue

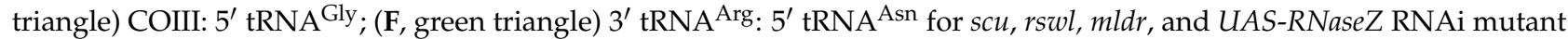
larvae. The arrow within each tRNA diagram indicates the internal primer start site for qPCR analysis. The red circled nucleotides represent $5^{\prime}->3^{\prime} \mathrm{mtRNA}$, and the blue represents mt:tRNA encoded on the opposite strand. Bars on the graphs represent averaged $2^{\wedge} \mathrm{ddCt}$, and the $\mathrm{y}$-axis is $\log _{2}$. Further explanation can be found in the materials and methods. The statistical significance was calculated relative to control $(y w)$. Error bars: S.E.M. calculated using GraphPad PRISM using an unpaired $t$-test, one-tailed. ${ }^{*} p<0.05{ }^{* *} p<0.01 ;{ }^{* * *} p<0.001$; ${ }^{* * *} p<0.0001$; ns: not significant. 


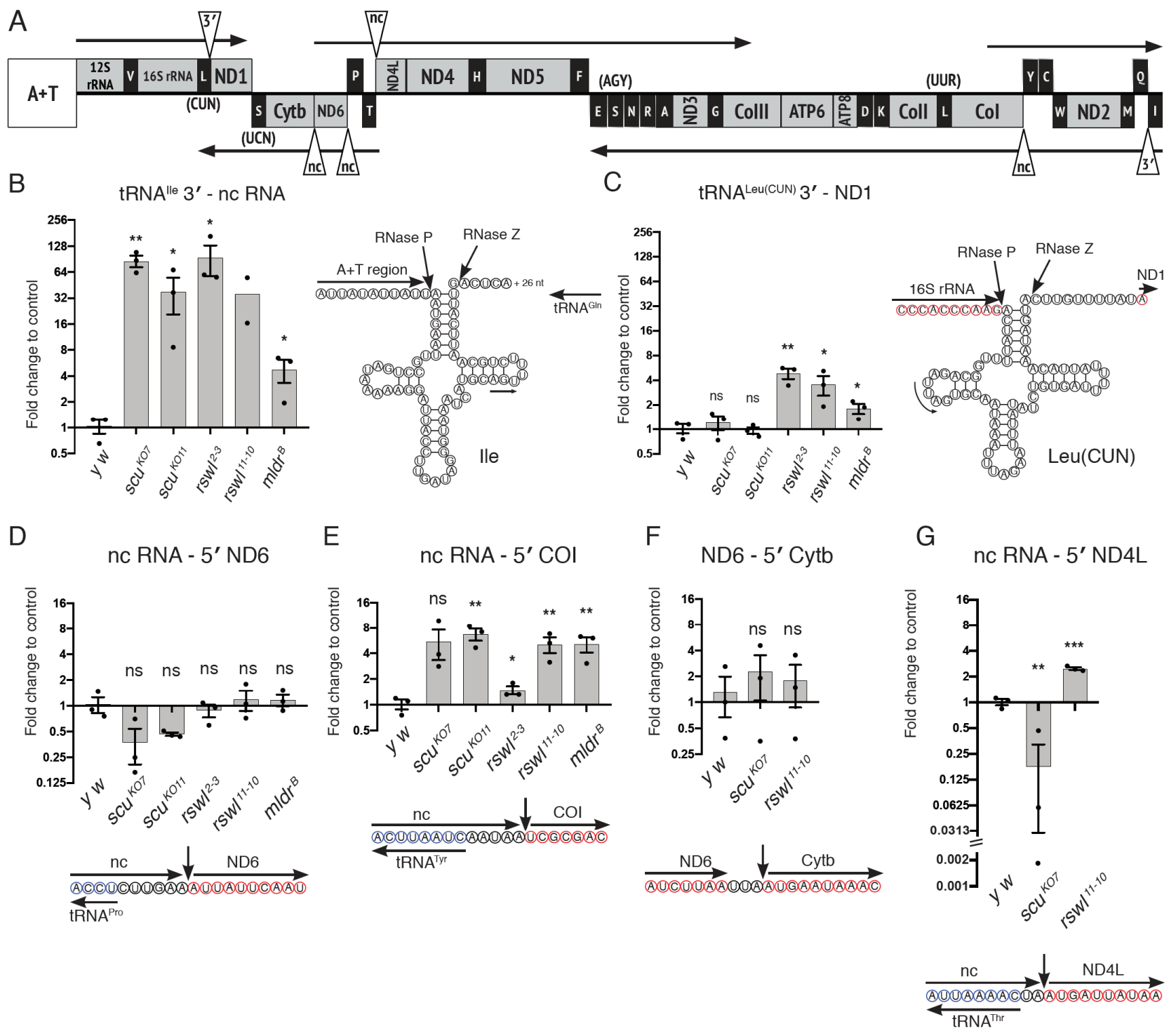

Figure 4. mt:tRNA $3^{\prime}$-end and non-canonical processing are differentially affected by mtRNase P. (A) Linear schematic of Drosophila circular mtDNA with triangles indicating the mt:tRNA $3^{\prime}$-end junctions and non-canonical junctions assayed. $\mathrm{A}+\mathrm{T}$ indicates the adenine and thymine-rich non-coding region that controls replication. $(\mathbf{B}, \mathrm{C})$ Graphs represent the log 2 fold change in qPCR levels in $s c u, r s w l$, and mldr mutant larvae for $3^{\prime}$-end junctions between tRNA ${ }^{\text {Ile }} 3^{\prime}$ : non-coding (nc) RNA (B); tRNA ${ }^{\text {Leu(CUN) }} 3^{\prime}$ : ND1 (C); ncRNA: 5' ND6 (D); ncRNA: 5' COI (E); ND6: 5' Cytb (F); ncRNA: 5' ND4L (G). The corresponding predicted cloverleaf structure of mt:tRNA $(B, C)$ or nucleotide context of the $5^{\prime}$-end cleavage site (D-G). The internal mt:tRNA forward primer is indicated with an arrow (B,C). Red circled nucleotides represent $5^{\prime} \rightarrow 3^{\prime}$ mtRNA, and blue represent the mt:tRNA encoded on the opposite strand. Bars on the graphs represent averaged $2^{\wedge} \mathrm{ddCt}$, and the $\mathrm{y}$-axis is $\log _{2}$. Further explanation can be found in the materials and methods. The statistical significance was calculated relative to control $(y w)$. Error bars: S.E.M. calculated using GraphPad PRISM using an unpaired $t$-test, one-tailed. ${ }^{*} p<0.05$; ${ }^{* *} p<0.01 ;{ }^{* * *} p<0.001$; ns: not significant. 
A

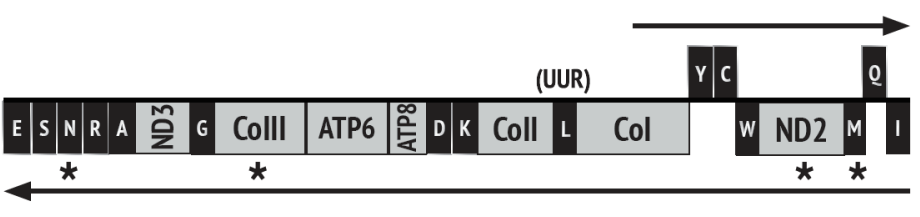

B

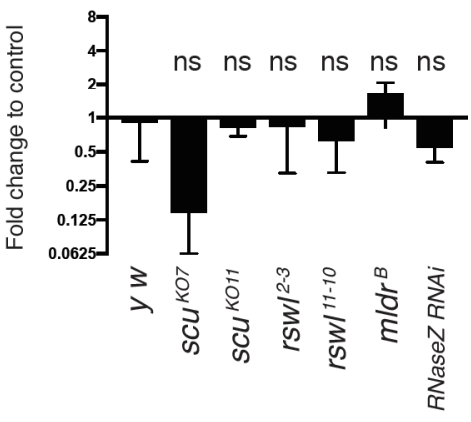

$\mathrm{D}$

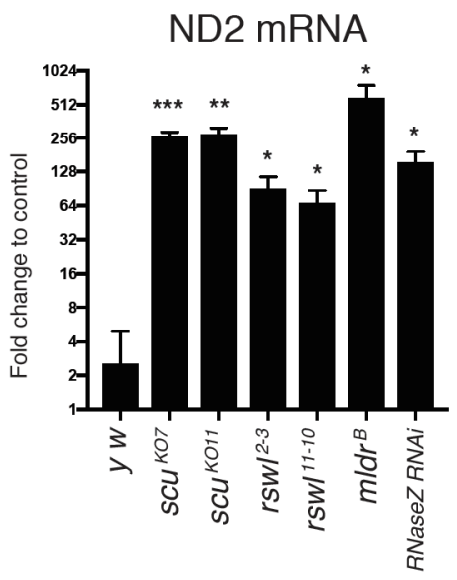

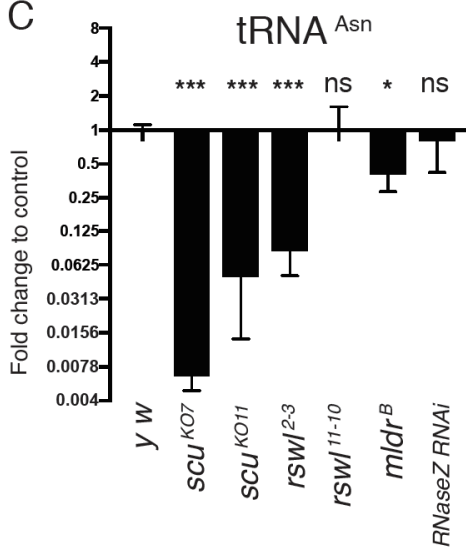

$\mathrm{E}$

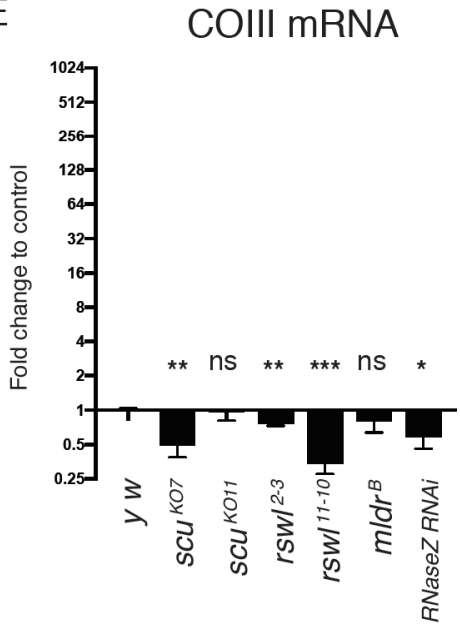

Figure 5. Steady state levels of mt:tRNAs and mt:mRNAs in mtRNase P mutants. (A) Graph of the analyzed mtRNA species (asterisks) located on the same polycistronic transcript. The graphs

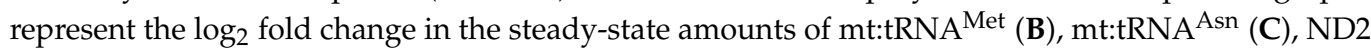
mRNA (D), and COIII mRNA (E) in scu, rswl, mldr, and RNaseZ RNAi mutants. Bars on the graphs represent averaged $2 \wedge \mathrm{ddCt}$, and the $\mathrm{y}$-axis is $\log _{2}$. Further explanation can be found in the materials and methods. Error bars: S.E.M. calculated in GraphPad PRISM. $p$-values were calculated using GraphPad PRISM using an unpaired $t$-test, two-tailed, and compared each mutant to the $y w$ control. ${ }^{*} p<0.05 ;{ }^{* *} p<0.01 ;{ }^{* * *} p<0.001$; ns: not significant.

\section{Discussion}

\subsection{Protein Null Mutants for In Vivo Analysis of All Three RNase P Complex Members}

The human mitochondrial diseases caused by mutations in $\mathrm{mtRNase} P$ proteins are severe, mostly leading to infantile to juvenile lethality $[22,26]$. There are multiple mutations identified in each protein leading to disease symptoms, but the age of onset of the disease, the severity, and the symptoms vary between mutations in the same protein. Additionally, MRPP2 and MRPP1 are multifunctional proteins which makes teasing out the effect of mutations in vivo challenging. Most information on mt:tRNA processing has been collected from cultured patient fibroblasts and protein knockdown experiments in cultured cells. MRPP3 and MRPP2 conditional knockout mice are available, which has been particularly helpful with respect to characterizing MRPP3 function in vivo $[19,28]$. However, the effect 
of reducing all three proteins in the mtRNase P complex on specific mt:tRNA junction processing has not been systematically examined in vivo. In order to do this, we created and confirmed protein null alleles for $r s w l$, scu, and mldr, allowing a comparative analysis of the effect of each protein on development and junction processing.

\subsection{Analyzing Specific mt:tRNA Junction Processing In Vivo}

In vitro studies using purified proteins to test cleavage of a single exogenously added (pre)mt:tRNA have yielded much information on enzyme kinetics, the importance of the MRPP1/2 subcomplex and enzymatic activity requirements for methyltransferase (MRPP1) and endonuclease (MRPP3) activity, including the effect of pathogenic mutations on cleavage [18,44,45]. Additional experiments have used RNAi knockdown in cell culture lines, such as HeLa cells, or patient-derived cultured fibroblasts $[4,5,26,46]$. In vivo work has been performed in Drosophila, and for MRPP2 and 3, using a tissue-specific knockdown in mice $[15,19,29]$. The consistent conclusion from these studies is that the lack of any mtRNase P component causes the accumulation of larger mtRNA species. Using an MRPP3 heart-specific conditional knockout mouse model, Rackham et al. showed defects in mtRNA processing, and their data support a model by which $5^{\prime}$-end processing precedes $3^{\prime}$-end processing. However, the effect of a knockdown of each mtRNAse P protein on specific junction processing has not been examined in vivo. In addition, an advantage of in vivo analysis is the potential to help identify unknown mechanisms or co-factors that can potentially carry out mtRNA processing in the absence of mtRNase P. For example, S-adenosyl methionine (SAM) has recently been shown to act as a co-factor necessary for MRPP1 function in vitro but not for its methyltransferase activity [44]. Previously, we found loss of Rswl (MRPP1), Scu (MRPP2), and Mldr (MRPP3) caused an accumulation of larger mtRNA species [29]. To more precisely test the requirement of each protein specifically on $5^{\prime}$ - or $3^{\prime}$-end junction processing, we designed primers for qPCR that spanned single junctions. This allowed us to directly measure processing of $5^{\prime}$ - or $3^{\prime}$-end junctions in different mtRNA contexts with loss of Scu, Rswl, or Mldr. Many of the findings support previously published data; however, we found certain junctions are differentially affected by the loss of specific mtRNase P complex members in Drosophila.

MRPP1 is responsible for the methylation of $\mathrm{m}^{1} \mathrm{G} 9$ or $\mathrm{m}^{1} \mathrm{~A} 9 \mathrm{in} \mathrm{mt}: \mathrm{RNAs}$. It is not known when methylation happens in vivo-before, during, or after cleavage. This RNA methylation can either block the action of reverse transcriptase or cause it to misincorporate a nucleotide. If this methylation blocks reverse transcription of RNA isolated from wildtype larvae, the resulting amount of cDNA across the $5^{\prime}$-end junction could be artificially decreased, thus enhancing the relative amount of unmethylated product present in the mutant extract. However, for this to be the case, it would assume that methylation precedes cleavage or that they are tightly coupled. In vitro data from the Rossmanith lab indicated that while mt:tRNA can be methylated by the holoenzyme, methylation, and cleavage are, in fact, uncoupled [9]. In addition, reconstituted mtRNase P with a methyltransferasedead MRPP1 was still able to cleave (pre)mt:tRNA [9]. Processing is known to be highly efficient in wild-type conditions in vivo; thus, we would expect to capture very low levels of steady-state unprocessed mt:tRNA junctions in normal wild-type larvae [29]. The qPCR data could also be affected by differential mtRNA stability in wild-type versus mutant extract. Transcripts derived from the heavy strand of human mtDNA showed differential stability in the absence of LRPPRC, a protein that regulates mtRNA stability [43]. While we did see an effect on levels of ND2 (increased), mt:tRNA ${ }^{\text {Asn }}, \mathrm{mt}_{\mathrm{tRNA}}{ }^{\mathrm{Met}}$, and COIII were either the same or decreased in mutant extract compared to wild-type. Importantly, differences in unprocessed junction accumulation for mt:tRNA ${ }^{\text {Asn }}$ and mt:tRNA ${ }^{\text {Met }}$ did not correlate with differences in total mt:tRNA levels (Figures 3 and 5). Therefore, we believe our observed accumulation of unprocessed junctions using this method reflects the amount of mtRNA processing occurring in vivo. 


\subsection{Canonical Junction Cleavage Is Most Affected by the Loss of Rswl}

We tested four canonical mt:tRNA $5^{\prime}$-end sites for processing (Figure 3) with each junction in a different RNA context which could potentially affect cleavage site recognition. The preceding transcript sequence was either directly juxtaposed to the $\mathrm{mtRNase} P$ cleavage site (Figure 4D,F), or there was a larger (Figure 4C) or smaller (Figure 4E) number of noncoding nucleotides preceding the cleavage site. In addition, within the polycistronic transcript, there could be positional information from mt:tRNA folding within the forward sequence (Figure $4 \mathrm{~F}, \mathrm{mt}_{\mathrm{t}} \mathrm{RNA}^{\mathrm{Arg}}$ ) or in mirror mt:tRNA (Figure $4 \mathrm{C}, \mathrm{mt}^{\mathrm{t}} \mathrm{tRNA}{ }^{\mathrm{Gln}}$ ) [41]. The MRPP1/2 subcomplex is thought to first bind mt:tRNA for correct positioning for subsequent cleavage by MRPP3 [16]. While the loss of Rswl, Scu, and Mldr resulted in an unprocessed junction for mt:tRNA ${ }^{\text {Met }}$ and mt:tRNA ${ }^{\text {Leu(CUN) }}$, only the loss of Rswl resulted in increased junction for mt:tRNA Gly, which was somewhat unexpected. If the $5^{\prime}$-end of $m t: t R N A$ Gly relies on mtRNAse $\mathrm{P}$, one would predict missing any of the mtRNase $\mathrm{P}$ components would disrupt mtRNA transcript processing. In addition, the loss of Scu should have the same effect as the loss of Rswl since MRPP2 forms a tight subcomplex with MRPP1 [9] and is required for mt:tRNA methylation [47] and patient-derived HSDB10 fibroblasts and siRNA knockdown of MRPP2 leads to decreased MRPP1 protein [15]. The greater effect of Rswl loss on unprocessed junctions was consistent with in vitro experiments showing loss of MRPP1 caused the largest accumulation of unprocessed mtRNA junctions [5], although Sanchez et al. did not test MRPP2 knockdown. However, in contrast, the MRPP3 conditional mouse knockout caused accumulation of mt:tRNA ${ }^{\mathrm{Gly}}$ 5 '-ends based on parallel analyses of RNA ends (PARE) analysis [19] and also qPCR, although to a lesser degree than MRPP1 knockdown [5]. For this mt:tRNA junction, in vivo, Rswl may have additional methylation functions that, when lost, could cause unprocessed mtRNA accumulation through an unknown mechanism. Further enzymatic analysis of $\mathrm{mtRNase} P$ from larval extract will be required in the future to determine the mechanism.

\subsection{Loss of Rswl Affects Processing within a Cluster of mt:tRNAs in Drosophila}

tRNAs are believed to start building nascent secondary structures right after transcription due to energetically favorable hydrogen bonding [48]. Drosophila mtDNA encodes for a stretch of five mt:tRNAs and one mirror mt:tRNA that is closely juxtaposed (Figure 3B,F). This organization is similar to a cluster of four mt:tRNAs and one mirror mt:tRNA in human mtDNA (Figure 3A), although the mt:tRNAs encoded are not the same. Due to this arrangement, efficient cleavage at either the $5^{\prime}$ - or $3^{\prime}$-end could remove the mt:tRNAs from the transcript (Figure 3F). In cultured HeLa cells, ELAC2 and MRPP1 RNAi caused a significant accumulation of mtRNA flanking ND2-tRNA ${ }^{\text {Ala }}$, although the specific primers used for the qPCR analysis are unclear [5]. In contrast, primers flanking the entire five-mt:tRNA cluster (ND2-COI) had a much smaller effect. In our analysis, loss of only one allele of $r s w l$ accumulated unprocessed junction for mt:tRNA ${ }^{\text {Asn }}$, the middle mt:tRNA (Figure 3B,F). In addition, RNase Z RNAi had a significant accumulation of product (Figure 4F), indicating the $3^{\prime}$-end cleavage of mt:tRNA ${ }^{\text {Arg }}$ could not compensate for the loss of $r s w l$. These results are consistent with Sanchez et al. Loss of Scu had no effect, in a similar manner to mt:tRNA ${ }^{\text {Gly }}$ (Figure 3E). While the loss of Mldr trended towards normal, we were unable to get the primer pair working sufficiently well to be able to draw a conclusion.

\section{5. mt:tRNA Processing Is Not Always Dependent on Scu}

Previous work examining an MRPP3 conditional knock-out mouse used PARE and RNAseq to investigate the degree to which loss of MRPP3 affected the presence of $5^{\prime}$ ends [19]. Rackham et al. found loss of $5^{\prime}$-end processing also reduced $3^{\prime}$-end processing gave rise to a hierarchical cleavage model whereby $\mathrm{mtRNAse} P$ activity is required before ELAC2 is able to cleave. This observation agrees with in vitro studies showing $3^{\prime}$-end cleavage by ELAC2 is enhanced in the presence of MRPP1/2 [16]. We examined $3^{\prime}$-end cleavage of mt:tRNA ${ }^{\text {Ile }}$ and found the loss of Rswl, Scu, and Mldr caused an increase in $3^{\prime}$-end unprocessed junctions in agreement with this model. We also examined mt:tRNA ${ }^{\mathrm{Leu}(\mathrm{CUN})}$ 
(Figure 4C). The loss of Rswl and Mldr accumulated unprocessed junctions, also in agreement. However, as with our $5^{\prime}$-end analysis (Figure 3), the loss of Scu did not accumulate unprocessed junction. The primers for this junction were internal for mt:tRNA ${ }^{\mathrm{Leu}(\mathrm{CUN})}$ and ND1, thus covering the $3^{\prime}$ - and $5^{\prime}$-ends for each transcript, respectively (Table S1). Thus, loss of Scu also did not affect $5^{\prime}$-end cleavage of ND1. Again, this was surprising as the MRPP2 homotetramer is thought to form a highly stable subcomplex with MRPP1, but these results suggest in the absence of Scu, cleavage could still occur. While the organization of this region is the same between Drosophila and human, the human polycistronic transcript has only two nucleotides between the RNase $Z$ cleavage site on mt:tRNA ${ }^{\text {Leu(CUN) }}$ and the start of ND1, whereas Drosophila has ten nucleotides. Perhaps this slightly larger gap changes enzyme kinetics between the two species.

We also examined several sites with junctions that are not predicted to be recognized by mtRNase P (non-canonical). Some of these junctions are unique to Drosophila, while some have a somewhat similar structure in humans. The $5^{\prime}$-end of ND6 was unaffected by the loss of Scu, Rswl, and Mldr. This is similar to Cytb processing in the MRPP3 conditional knockout mouse, which is located in a similar genomic organization [19]. In contrast, the $5^{\prime}$-end of COI was affected by the loss of all three proteins (Figure 4E) even though there is a mirror mt:tRNA ${ }^{\text {Tyr }}$ upstream, which is similar to $5^{\prime}$-end ND6. Finally, the two unique junctions, $5^{\prime}$-end Cytb (Figure 4F) and $5^{\prime}$-end ND4L (Figure 4G) appeared either unaffected or only affected by rswl, respectively, although we only tested one allele of each. The data for the non-canonical junctions support the notion that there are additional mechanisms for the cleavage of $5^{\prime}$-end junctions in some instances [19].

\section{6. mtRNase P Action In Vivo}

While mtRNAse $P$ is clearly critical for $5^{\prime}$-end mt:tRNA processing, there is increasing support that other unidentified proteins or mechanisms may be involved in this process. Careful in vitro analysis has tested the requirement of the MRPP1/2 subcomplex and MRPP3 on $5^{\prime}$-end cleavage and methylation. However, this is the first time the individual proteins were removed in vivo and tested for their ability to process specific junctions. There is a rising consensus that Rswl/MRPP1 is the most critical protein, likely due to its strict requirement for MRPP3 cleavage and its enzymatic function as a methylase. Thus, it is not surprising junction processing is most sensitive to loss of Rswl. What is unusual is that Scu (Figures 3E,F and 4C) and even occasionally Mldr (Figure 3E) appeared to be dispensable for certain junctions. One possibility is that there are additional mechanisms in vivo that can partially rescue the loss of mtRNase P. mtRNase P does not have an RNA component [4]. However, RNase P RNA activity has been copurified with mitochondria, and the RNA binds to PNPase to process mtRNA [49,50]. In addition, the nuclear DNAencoded lncRNA mitochondrial RNA processing endoribonuclease (RMRP), which cleaves and processes rRNA in the nucleus, is in the mitochondrial matrix [51]. Thus, there are likely additional mechanisms that can compensate for the loss of one or more members of mtRNase $P$ in vivo.

Mitochondrial diseases are pleiotropic, affecting multiple organs and systems. With only palliative care available, identifying the basic molecular mechanisms underlying these complex diseases is paramount to understanding disease etiology and progression. Drosophila has emerged as an excellent model for studying mitochondrial diseases that can be used to better understand how the loss of individual proteins affects the basic cellular biology underlying mitochondrial dysfunction [52,53]. Modeling mitochondrial diseases in Drosophila has the advantage of balancing a fast life cycle and well-developed genetics with somewhat complex organ systems that often have an analogous function to humans [54]. In humans, mutations in each of the mtRNase P subunits, as well as mtDNA mutations affecting the cleavage site, can cause loss of mt:tRNA cleavage and processing, which ultimately leads to mitochondrial disease. Using the strengths of Drosophila genetics, we have tested the loss of all three mtRNase P subunits in vivo and how this loss alters the cleavage of specific mt:tRNA junctions. By measuring discrete junctions, we found 
differential requirements of specific junctions for mtRNase P complex members and also apparent differences in processing which may be dependent on the flanking regions. These data start to tease apart the requirements for each protein and suggest there are additional mechanisms that can compensate for the loss of specific mtRNAse P components. Understanding the role of $\mathrm{mtRNase} P$ in Drosophila offers the opportunity to model diseases caused by aberrant mtRNase $P$ function and could ultimately aid in further understanding of disease progression.

\section{Materials and Methods}

\subsection{Fly Stocks}

The following stocks were obtained from Bloomington stock center: $\mathrm{P}(\mathrm{PZ}) \mathrm{rsw} \mathrm{l}^{07838}$ $\mathrm{cn}^{1} / \mathrm{CyO} ; \mathrm{ry}^{506}, \mathrm{Ab}(1) \mathrm{os}^{\mathrm{s}} ; \mathrm{y}^{1} \mathrm{w}^{*} \mathrm{scu}^{4058}$ upd1 ${ }^{\text {os-s }}$ upd $3^{\text {os-s }} / \mathrm{FM} 6 ; \mathrm{y}^{1} \mathrm{w}^{*} \mathrm{scu}^{\mathrm{A}}$ FRT19A/FM7i, ActGFP; $y^{1} w^{*}$ scu $^{D}$ FRT19A/FM7i, ActGFP; $y^{1} w^{*}$ mldr $^{B}$ FRT19A/FM7i, ActGFP; ${ }^{1}$ $\mathrm{w}^{*}$ mldrC FRT19A/FM7i, ActGFP; $\mathrm{y}^{1} \mathrm{sc}^{*} \mathrm{v}^{1} \mathrm{sev}^{21} ; \mathrm{P}\left(\mathrm{TKO}\right.$.GS00939)attP40; $\mathrm{y}^{1} \mathrm{sc}^{*} \mathrm{v}^{1}$; scuTRiPGL01079; $\mathrm{y}^{1} \mathrm{w}^{*} ; \mathrm{P}(\mathrm{w}[+\mathrm{mC}]=$ tubPGAL4)LL7/TM3, $\mathrm{P}(\mathrm{w}[+\mathrm{mC}]=$ ActGFP $) J M R 2$, Ser $^{1} ; \mathrm{y}^{1} \mathrm{w}^{*} ; \mathrm{P}\left(\mathrm{w}[+\mathrm{mC}]=\right.$ Act5C-GAL4) 17bFO1/TM3, $\mathrm{P}(\mathrm{w}[+\mathrm{mC}]=$ ActGFP $) J M R 2$, Ser; $\mathrm{y}^{1}$ $\mathrm{M}$ (vas-Cas9)ZH-2A w ${ }^{1118}$ /FM7c. The following stocks were obtained from the Vienna Drosophila Research Center: $\mathrm{y} \mathrm{w}^{1118} ; \mathrm{mldr}^{\mathrm{KK} 108043} ; \mathrm{w}^{1118} ; \mathrm{rswl}^{\mathrm{GD} 12447} ; \mathrm{w}^{1118} ; \mathrm{P}(\mathrm{GD} 10927)$ v43752. The following stock was obtained from the Drosophila Research and Screening Center-Biomedical Technology Research Resource, Harvard Medical School: $\mathrm{y}^{1} \mathrm{sc}^{*} \mathrm{v}^{1}$ $\mathrm{P}($ nos-Cas9) attp2.

\subsection{Transgenic Flies and Crosses}

$r s w l$ and $s c u$ knockout flies were generated using CRISPR/Cas9. For $r s w l$, two guide RNAs complementary to the $5^{\prime}$ - and $3^{\prime}$-ends were used. The guide RNAs were commercially cloned in pU6-Bbsl-chiRNA vector (Genewiz, Plainfield, NJ, USA) expressing the chiRNA under the control of the Drosophila snRNA:U6:96Ab promoter [55] (Addgene, Watertown, MA, USA). $250 \mathrm{ng}$ of each guide RNA expressing plasmid was commercially injected into $y^{1} \mathrm{M}(v a s-C a s 9) \mathrm{ZH}-2 \mathrm{~A} w^{1118} / F M 7 \mathrm{c}$ stock, stably expressing Cas9 under the control of the germline-specific vasa promoter (BestGene Inc., Chino Hills, CA, USA). Positive second filial (F2) flies were confirmed by sequencing. For scu CRISPR knockouts, transgenic flies stably expressing guide complementary to the $5^{\prime}$-end of the protein-coding region (generated by Harvard Medical School, DRSC/TRiP Functional Genomics Resources) were crossed with flies stably expressing Cas9 under the control of the germline specific nos promoter. Positive F2 flies were confirmed by sequencing.

\subsection{Roswell and Scully Antibody Generation}

The Drosophila ESTs rswl (LD44982) and scu (IP05285) (Drosophila Genomics Resource Center, Bloomington, IN, USA) were cloned into a p-DEST vector and transformed into BL21(DE3) cells. Transformed clones were grown at $37{ }^{\circ} \mathrm{C}$ for $5 \mathrm{~h}$ and induced with $0.4 \mathrm{mM}$ IPTG at $18^{\circ} \mathrm{C}$ overnight. The cells were harvested and lysed with sonication in binding buffer ( $5 \mathrm{mM}$ imidazole, $500 \mathrm{mM} \mathrm{NaCl}, 20 \mathrm{mM}$ Tris $\mathrm{pH} 7.9$, and $6 \mathrm{M}$ guanidine hydrochloride). Proteins were isolated and purified using HisPur Ni-NTA resin column (Fisher Scientific, Waltham, MA) as per the manufacturer's recommended protocol. The proteins were washed in wash buffer ( $30 \mathrm{mM}$ imidazole, $500 \mathrm{mM} \mathrm{NaCl}, 20 \mathrm{mM}$ Tris $\mathrm{pH} 7.9$, and $6 \mathrm{M}$ guanidine hydrochloride) and eluted in elution buffer ( $300 \mathrm{mM}$ imidazole, $500 \mathrm{mM}$ $\mathrm{NaCl}, 20 \mathrm{mM}$ Tris $\mathrm{pH} 7.9$, and $6 \mathrm{M}$ urea). The protein samples were pooled, concentrated, and their purity was checked by SDS-PAGE. Full-length protein samples were then sent for commercial injections into guinea pigs (Rswl) or rats (Scu) (Covance Research Products, Inc., Denver, PA, USA).

\subsection{Pupation and Eclosion Rates}

Pupation and eclosion rates were calculated as previously described [29]. In short, twenty non-GFP (mutant) first instar larvae were transferred into vials at room temperature. 
The number of pupae was counted every $24 \mathrm{~h}$. The number of eclosed adults was counted each day after the onset of eclosion. For each genotype, the experiment was performed in triplicates. The fly food was kept moist using water drops to avoid drying. The average and standard deviation calculations were done using GraphPad PRISM and Microsoft Excel.

\subsection{Immunofluorescence}

Immunofluorescence was performed on samples as previously described [29]. In short, larval brains and ovaries from well-fed adult females were dissected in Grace's insect medium (BioWhittaker, Lonza, Cologne, Germany) and fixed in Grace's medium containing $4 \%$ paraformaldehyde and $20 \mathrm{mM}$ formic acid (Sigma, St. Louis, MO, USA). Antibody staining was performed overnight at $4{ }^{\circ} \mathrm{C}$ in antibody wash buffer (1X PBS, $0.1 \%$ TritonX-100, 1\% BSA). The following primary antibodies were used: guinea pig anti-Rswl (1:500) (this work), rat anti-Scu (1:500) (this work), mouse anti-ATP5A (15H4C4) (1:750) (Cat\# ab14748) (Abcam, Cambridge, UK). Following primary antibody labeling the samples were washed $3 x$ in antibody wash buffer and labeled with secondary antibodies overnight at $4{ }^{\circ} \mathrm{C}$. The following secondary antibodies were used: goat anti-guinea pig IgG Alexa 488 (Cat\# A-11073), goat anti-mouse IgG2b Alexa 568 (Cat\# A-21144), goat anti-mouse IgG Alexa 488 (Cat\# A-11001) (1:500) (Molecular Probes, Invitrogen, Carlsbad, CA, USA), and donkey anti-rat IgG Cy3 (1:500) (Cat\# 712-165-153) (Jackson Labs, West Grove, PA, USA). After washing $3 x$ in antibody wash buffer, DAPI was added to the samples for five minutes before treating with Vectashield (Vector Laboratories, Inc., Burlingame, CA, USA) overnight at $4^{\circ} \mathrm{C}$. For labeling actin in the neuroblast cells, rhodamine-phalloidin (1:1000) (Cat\# A12380) (Molecular Probes, Invitrogen, Carlsbad, CA, USA) was used along with primary antibody. Images were collected using Zeiss 700 confocal microscope $63 \times$ Plan Apo NA 1.4 lens.

\subsection{ATP Assay}

ATP assays were performed as previously described [29]. In short, age-matched wildtype and mutant larvae were collected and homogenized in ATP extraction buffer (100 mM Tris-Cl, pH 8.0, 4 mM EDTA, pH 8.0, and $6 \mathrm{M}$ guanidine hydrochloride) and used for both ATP and bicinchoninic acid (BCA) assay. ATP concentrations were determined using ATP determination Kit (Invitrogen, Thermo Fischer Scientific, Waltham, MA, USA) as per the manufacturer's protocol. The luciferase activity was measured in 96-well format using a CLARIOstar plate reader (BMG Labtech Inc., Cary, NC, USA). Protein concentrations were determined using a BCA assay. $5 \mu \mathrm{L}$ of diluted samples (1:50) were mixed with $100 \mu \mathrm{L}$ of BCA reagent (Pierce BCA protein assay Kit, Thermo Fischer Scientific, Waltham, MA, USA), and protein concentrations were measured on a CLARIOstar plate reader (BMG Labtech Inc., Cary, NC, USA). Results were averaged over three (Rswl) or five (Scu) technical replicates and represented as ATP concentrations normalized to the protein concentrations.

\subsection{Western Blots}

Western blots were performed as previously described [29]. For determining the protein levels in mutants and wild-type, homogenized first instar larval extracts collected in $1 \times$ PBS were used. For the antibody specificity experiment, mitochondrial pellet and cytoplasmic extract were isolated as per the manufacturer's instructions (Mitochondria Isolation Kit for Cultured Cells, Thermo Scientific, Waltham, MA, USA). For the maternal deposition experiment, homogenized extracts of either stage 14 eggs, dissected from the ovaries of well-fed females, or mutant embryos collected $16 \mathrm{~h}$ after egg laying were collected in $1 \times$ PBS. The antibodies used for Western blots were guinea pig anti-Rswl (1:3333) (this work), rat anti-Scu (1:3333) (this work), rabbit anti-Mldr (1:3333) [29], mouse anti-ATP5A (15H4C4) $(1: 100,000)$ (Cat\# ab1474) (Abcam, Cambridge, UK), and mouse anti- $\alpha$-tubulin (1:3333) (Cat\# AA4.3) (Developmental Studies Hybridoma Bank, University of Iowa, Iowa City, IA, USA). Antibodies used for loading controls were obtained in parallel. 


\section{8. $q P C R$}

RNA was isolated from 100 age-matched one-day-old larvae using mirVana miRNA Isolation Kit (Invitrogen, Thermo Fisher Scientific, Waltham, MA) as per the manufacturer's recommended protocol. $250 \mathrm{ng}$ of RNA was reverse transcribed using a High-Capacity cDNA Reverse Transcription kit (Applied Biosystems, Foster City, CA, USA) following the manufacturer's recommendation. For gene expression analysis, quantitative PCR was performed using TaqMan Gene Expression Master Mix (Applied Biosystems, Foster City, CA, USA) in a 10 ul reaction with $1 \mu \mathrm{L}$ undiluted cDNA and one of the following TaqMan probes: Dm01827021_s1 (rswl), Dm02362013_s1 (scu), Dm01833186_g1(mldr), Dm02151827_g1 (RPL32) (endogenous control) and Dm01812859_g1 (RNase Z) (Thermo Fisher Scientific, Waltham, MA). For junction quantitative PCR, $1 \mu \mathrm{L}$ of cDNA diluted to $1: 10$ was used in a $10 \mu \mathrm{L}$ reaction with Platinum SYBR Green qPCR SuperMix-UDG (Invitrogen, Carlsbad, CA) and specific primers (Supplemental Table S1) adopted from Clemente et al. [56]. qPCR was performed in triplicates for each genotype, and the delta delta $\mathrm{Ct}(\mathrm{ddCt}$ ) calculations were performed using reference RNA for RpL32 (gene qPCR) or $18 \mathrm{~S}$ (junction qPCR) as endogenous controls and $y w$, as a wild-type control. Shown below are the general calculations for junction qPCR:

$\mathrm{dCt}$ junction $=\mathrm{Ct}($ junction $)-\mathrm{Ct}(18 \mathrm{~S}$ reference $)$ [within each sample]

$\mathrm{ddCT}=\mathrm{dCt}$ (mutant)- $\mathrm{dCt}(y w$ control)

[dCt $(y w$ control $)=($ mean Ct(junction $)$-mean Ct $(18 \mathrm{~S}$ reference $)]$

We represented the values for $y w$ control on the graphs for additional ease of comparison between mutant and wild-type. For the $y w$ bars, we calculated the ddCt as follows:

$\mathrm{ddCt}=\mathrm{dCt}(y w$ control, individual $\mathrm{dCt})-\mathrm{dCt}(y w$ control, mean Ct(junction) -mean $\mathrm{Ct}(18 \mathrm{~S}$ reference) $)$

Each bar on the graph represents the average of three $2^{\wedge} \mathrm{ddCt}$ to better represent the exponential nature of PCR. The error bars represent the standard error of mean (S.E.M.) calculated with the $2^{\wedge} \mathrm{ddCt}$ values. $p$-values were calculated using an unpaired $t$-test, onetailed, and used to compare each individual mutant vs. $y w$ (wild-type). The hypothesis we were testing was that there was a difference between wild-type and mutant in the amount of available intact mtRNA across each junction that can give rise to PCR product $(\mathrm{dCt})$ and our null hypothesis was that the $\mathrm{dCt}$ values were equal between wild-type and mutants. Since $\mathrm{dCt}$ values have a normal distribution due to the nature of the assay, we used a $t$-test to compare the significance between ddCt of product from wild-type and ddCt of product from mutant. We used one-tailed for the junction analysis because we were measuring less efficient transcript processing and thus increases in PCR product across the junction compared to wild-type and were not testing more efficient transcript processing with concomitant decreases in PCR product. Since we were testing for positive and negative changes for the qPCR measuring mtRNA for genes, we used a two-tailed analysis. The $\mathrm{dCt}$ calculations were performed in Microsoft Word Excel. The S.E.M. and $p$-values were calculated using GraphPad PRISM. The graphs were plotted using GraphPad PRISM.

Supplementary Materials: The following are available online at https:/ / www.mdpi.com/article/10 .3390 /ijms22116066/s1, Figure S1: scu and rswl CRISPR/Cas9 generated alleles. Figure S2: Additional analysis of $s c u, r s w l$, and $m l d r$ alleles, Figure S3: Rswl and Scu colocalize with mitochondria, Figure S4: mtRNase P is maternally loaded, Figure S5: Northern dot blot analysis of mt:tRNA ${ }^{\text {Asn }}$ and COIII levels, Table S1. List of qPCR primers, Supplemental Materials and Methods.

Author Contributions: Conceptualization, M.S. and R.T.C.; methodology, M.S., A.S. and R.T.C.; validation, M.S., A.S. and R.T.C.; formal analysis, M.S., A.S. and R.T.C.; writing-original draft preparation, M.S. and R.T.C.; writing-review and editing, R.T.C.; supervision, R.T.C.; funding acquisition, R.T.C. All authors have read and agreed to the published version of the manuscript.

Funding: This work was supported by the Collaborative Health Initiative Research Program (CHIRP) grant number HU0001-14-2-0041 and the National Institutes of Health grant number GM127938 (to R.T.C.)

Institutional Review Board Statement: Not applicable. 
Informed Consent Statement: Not applicable.

Acknowledgments: We would like to thank Venkat Gopalan and Lien Lai for their helpful discussions. We also thank the USU Biomedical Instrumentation Core for imaging support and The Developmental Studies Hybridoma Bank, created by the NICHD of the NIH and maintained at the University of Iowa, Department of Biology for the anti-tubulin antibody. The graphical abstract was created with BioRender.com.

Conflicts of Interest: The authors declare no conflict of interest. The funders had no role in the design of the study; in the collection, analyses, or interpretation of data; in the writing of the manuscript, or in the decision to publish the results.

\section{References}

1. Anderson, S.E.; Bankier, A.T.; Barrell, B.G.; De Bruijn, M.H.L.; Coulson, A.R.; Drouin, J.; Eperon, I.C.; Nierlich, D.P.; Roe, B.A.; Sanger, F.; et al. Sequence and organization of the human mitochondrial genome. Nature 1981, 290, 457-465. [CrossRef]

2. Montoya, J.; Gaines, G.L.; Attardi, G. The pattern of transcription of the human mitochondrial rRNA genes reveals two overlapping transcription units. Cell 1983, 34, 151-159. [CrossRef]

3. Ojala, D.; Montoya, J.; Attardi, G. tRNA punctuation model of RNA processing in human mitochondria. Nat. Cell Biol. 1981, 290, 470-474. [CrossRef] [PubMed]

4. Holzmann, J.; Frank, P.; Löffler, E.; Bennett, K.L.; Gerner, C.; Rossmanith, W. RNase P without RNA: Identification and Functional Reconstitution of the Human Mitochondrial tRNA Processing Enzyme. Cell 2008, 135, 462-474. [CrossRef] [PubMed]

5. Sanchez, M.I.L.; Mercer, T.R.; Davies, S.M.; Shearwood, A.-M.J.; Nygård, K.K.; Richman, T.R.; Mattick, J.S.; Rackham, O.; Filipovska, A. RNA processing in human mitochondria. Cell Cycle 2011, 10, 2904-2916. [CrossRef] [PubMed]

6. Altman, S. Ribonuclease P: An Enzyme with a Catalytic RNA Subunit. Adv. Enzymol. Relat. Areas Mol. Biol. 2006, 62, 1-36. [CrossRef]

7. Baer, M.F.; Wesolowski, D.; Altman, S. Characterization in vitro of the defect in a temperature-sensitive mutant of the protein subunit of RNase P from Escherichia coli. J. Bacteriol. 1989, 171, 6862-6866. [CrossRef] [PubMed]

8. Jackman, J.E.; Montange, R.K.; Malik, H.S.; Phizicky, E.M. Identification of the yeast gene encoding the tRNA m1G methyltransferase responsible for modification at position 9. RNA 2003, 9, 574-585. [CrossRef]

9. Vilardo, E.; Nachbagauer, C.; Buzet, A.; Taschner, A.; Holzmann, J.; Rossmanith, W. A subcomplex of human mitochondrial RNase $\mathrm{P}$ is a bifunctional methyltransferase-extensive moonlighting in mitochondrial tRNA biogenesis. Nucleic Acids Res. 2012, 40, 11583-11593. [CrossRef]

10. Luo, M.J.; Mao, L.F.; Schulz, H. Short-chain 3-hydroxy-2-methylacyl-CoA dehydrogenase from rat liver: Purification and characterization of a novel enzyme of isoleucine metabolism. Arch. Biochem. Biophys. 1995, 321, 214-220. [CrossRef]

11. Zschocke, J.; Ruiter, J.P.; Brand, J.; Lindner, M.; Hoffmann, G.F.; Wanders, R.J.; Mayatepek, E. Progressive infantile neurodegeneration caused by 2-methyl-3-hydroxybutyryl-CoA dehydrogenase deficiency: A novel inborn error of branched-chain fatty acid and isoleucine metabolism. Pediatr. Res. 2000, 48, 852-855. [CrossRef]

12. Gobert, A.; Gutmann, B.; Taschner, A.; Gössringer, M.; Holzmann, J.; Hartmann, R.K.; Rossmanith, W.; Giegé, P. A single Arabidopsis organellar protein has RNase P activity. Nat. Struct. Mol. Biol. 2010, 17, 740-744. [CrossRef] [PubMed]

13. Howard, M.J.; Lim, W.H.; Fierke, C.A.; Koutmos, M. Mitochondrial ribonuclease P structure provides insight into the evolution of catalytic strategies for precursor-tRNA 5' processing. Proc. Natl. Acad. Sci. USA 2012, 109, 16149-16154. [CrossRef] [PubMed]

14. Wang, M.J.; Davis, N.W.; Gegenheimer, P. Novel mechanisms for maturation of chloroplast transfer RNA precursors. EMBO J. 1988, 7, 1567-1574. [CrossRef]

15. Deutschmann, A.J.; Amberger, A.; Zavadil, C.; Steinbeisser, H.; Mayr, J.A.; Feichtinger, R.G.; Oerum, S.; Yue, W.W.; Zschocke, J. Mutation or knock-down of 17beta-hydroxysteroid dehydrogenase type 10 cause loss of MRPP1 and impaired processing of mitochondrial heavy strand transcripts. Hum. Mol. Genet. 2014, 23, 3618-3628. [CrossRef]

16. Reinhard, L.; Sridhara, S.; Hällberg, B.M. The MRPP1/MRPP2 complex is a tRNA-maturation platform in human mitochondria. Nucleic Acids Res. 2017, 45, 12469-12480. [CrossRef]

17. Liu, X.; Wu, N.; Shanmuganathan, A.; Klemm, B.P.; Howard, M.J.; Lim, W.H.; Koutmos, M.; Fierke, C.A. Kinetic mechanism of human mitochondrial RNase P. bioRxiv 2019, 666792. [CrossRef]

18. Karasik, A.; Fierke, C.A.; Koutmos, M. Interplay between substrate recognition, $5^{\prime}$ end tRNA processing and methylation activity of human mitochondrial RNase P. RNA 2019, 25, 1646-1660. [CrossRef] [PubMed]

19. Rackham, O.; Busch, J.D.; Matic, S.; Siira, S.; Kuznetsova, I.; Atanassov, I.; Ermer, J.A.; Shearwood, A.-M.J.; Richman, T.; Stewart, J.B.; et al. Hierarchical RNA Processing Is Required for Mitochondrial Ribosome Assembly. Cell Rep. 2016, 16, 1874-1890. [CrossRef]

20. Saoji, M.; Cox, R.T. Mitochondrial RNase P Complex in Animals: Mitochondrial tRNA Processing and Links to Disease. In Modified Nucleic Acids; Springer Science and Business Media LLC: Berlin/Heidelberg, Germany, $2018 ;$ pp. $47-71$.

21. Brandon, M.C.; Lott, M.T.; Nguyen, K.C.; Spolim, S.; Navathe, S.B.; Baldi, P.; Wallace, D.C. MITOMAP: A human mitochondrial genome database-2004 update. Nucleic Acids Res. 2004, 33, D611-D613. [CrossRef]

22. Zschocke, J. HSD10 disease: Clinical consequences of mutations in the HSD17B10 gene. J. Inherit. Metab. Dis. 2011, 35, 81-89. [CrossRef] [PubMed] 
23. Chatfield, K.C.; Coughlin, C.R., 2nd; Friederich, M.W.; Gallagher, R.C.; Hesselberth, J.R.; Lovell, M.A.; Ofman, R.; Swanson, M.A.; Thomas, J.A.; Wanders, R.J.; et al. Mitochondrial energy failure in HSD10 disease is due to defective mtDNA transcript processing. Mitochondrion 2015, 21, 1-10. [CrossRef] [PubMed]

24. Oerum, S.; Roovers, M.; Leichsenring, M.; Acquaviva-Bourdain, C.; Beermann, F.; Gemperle-Britschgi, C.; Fouilhoux, A.; KorwitzReichelt, A.; Bailey, H.J.; Droogmans, L.; et al. Novel patient missense mutations in the HSD17B10 gene affect dehydrogenase and mitochondrial tRNA modification functions of the encoded protein. Biochim. Et Biophys. Acta (BBA) Mol. Basis Dis. 2017, 1863, 3294-3302. [CrossRef]

25. Vilardo, E.; Rossmanith, W. Molecular insights into HSD10 disease: Impact of SDR5C1 mutations on the human mitochondrial RNase P complex. Nucleic Acids Res. 2015, 43, 5112-5119. [CrossRef]

26. Metodiev, M.D.; Thompson, K.; Alston, C.L.; Morris, A.A.; He, L.; Assouline, Z.; Rio, M.; Bahi-Buisson, N.; Pyle, A.; Griffin, H.; et al. Recessive Mutations in TRMT10C Cause Defects in Mitochondrial RNA Processing and Multiple Respiratory Chain Deficiencies. Am. J. Hum. Genet. 2016, 98, 993-1000. [CrossRef] [PubMed]

27. Hochberg, I.; Demain, L.A.M.; Urquhart, J.E.; Amberger, A.; Deutschmann, A.J.; Demetz, S.; Thompson, K.; O'Sullivan, J.; Belyantseva, I.A.; Barzik, M.; et al. A homozygous variant in mitochondrial RNase P subunit PRORP is associated with Perrault syndrome characterized by hearing loss and primary ovarian insufficiency. BioRxiv 2017. [CrossRef]

28. Rauschenberger, K.; Scholer, K.; Sass, J.O.; Sauer, S.; Djuric, Z.; Rumig, C.; Wolf, N.I.; Okun, J.G.; Kolker, S.; Schwarz, H.; et al. A non-enzymatic function of 17 beta-hydroxysteroid dehydrogenase type 10 is required for mitochondrial integrity and cell survival. EMBO Mol. Med. 2010, 2, 51-62. [CrossRef]

29. Sen, A.; Karasik, A.; Shanmuganathan, A.; Mirkovic, E.; Koutmos, M.; Cox, R.T. Loss of the mitochondrial protein-only ribonuclease P complex causes aberrant tRNA processing and lethality in Drosophila. Nucleic Acids Res. 2016, 44, 6409-6422. [CrossRef]

30. Claros, M.G.; Vincens, P. Computational Method to Predict Mitochondrially Imported Proteins and their Targeting Sequences. JBIC J. Biol. Inorg. Chem. 1996, 241, 779-786. [CrossRef]

31. Sievers, F.; Wilm, A.; Dineen, D.; Gibson, T.J.; Karplus, K.; Li, W.; López, R.; McWilliam, H.; Remmert, M.; Söding, J.; et al. Fast, scalable generation of high-quality protein multiple sequence alignments using Clustal Omega. Mol. Syst. Biol. $2011,7,539$. [CrossRef]

32. Bassett, A.R.; Tibbit, C.; Ponting, C.P.; Liu, J.-L. Highly efficient targeted mutagenesis of Drosophila with the CRISPR/Cas9 system. Cell Rep. 2013, 4, 220-228. [CrossRef]

33. Ren, X.; Sun, J.; Housden, B.; Hu, Y.; Roesel, C.; Lin, S.; Liu, L.-P.; Yang, Z.; Mao, D.; Sun, L.; et al. Optimized gene editing technology for Drosophila melanogaster using germ line-specific Cas9. Proc. Natl. Acad. Sci. USA 2013, 110, 19012-19017. [CrossRef]

34. Huser, J.; Blatter, L.A. Fluctuations in mitochondrial membrane potential caused by repetitive gating of the permeability transition pore. Biochem. J. 1999, 343 Pt 2, 311-317. [CrossRef]

35. Vander Heiden, M.G.; Chandel, N.S.; Williamson, E.K.; Schumacker, P.T.; Thompson, C.B. Bcl-xL regulates the membrane potential and volume homeostasis of mitochondria. Cell 1997, 91, 627-637. [CrossRef]

36. Berthier, F.; Renaud, M.; Alziari, S.; Durand, R. RNA mapping on Drosophila mitochondrial DNA: Precursors and template strands. Nucleic Acids Res. 1986, 14, 4519-4533. [CrossRef] [PubMed]

37. Taanman, J.-W. The mitochondrial genome: Structure, transcription, translation and replication. Biochim. Et Biophys. Acta (BBA) Bioenerg. 1999, 1410, 103-123. [CrossRef]

38. Torres, T.T.; Dolezal, M.; Schlötterer, C.; Ottenwälder, B. Expression profiling of Drosophila mitochondrial genes via deep mRNA sequencing. Nucleic Acids Res. 2009, 37, 7509-7518. [CrossRef]

39. Xie, X.; Dubrovskaya, V.A.; Dubrovsky, E.B. RNAi knockdown of dRNaseZ, the Drosophila homolog of ELAC2, impairs growth of mitotic and endoreplicating tissues. Insect Biochem. Mol. Biol. 2011, 41, 167-177. [CrossRef]

40. Brzezniak, L.; Bijata, M.; Szczesny, R.J.; Stepien, P.P. Involvement of human ELAC2 gene product in 3' end processing of mitochondrial tRNAs. RNA Biol. 2011, 8, 616-626. [CrossRef]

41. Szczesny, R.J.; Borowski, L.S.; Brzezniak, L.; Dmochowska, A.; Gewartowski, K.; Bartnik, E.; Stepien, P.P. Human mitochondrial RNA turnover caught in flagranti: Involvement of hSuv3p helicase in RNA surveillance. Nucleic Acids Res. 2009, 38, $279-298$. [CrossRef] [PubMed]

42. Mercer, T.R.; Neph, S.; Dinger, M.; Crawford, J.; Smith, M.A.; Shearwood, A.-M.J.; Haugen, E.; Bracken, C.P.; Rackham, O.; Stamatoyannopoulos, J.A.; et al. The Human Mitochondrial Transcriptome. Cell 2011, 146, 645-658. [CrossRef] [PubMed]

43. Ruzzenente, B.; Metodiev, M.D.; Wredenberg, A.; Bratic, A.; Park, C.B.; Cámara, Y.; Milenkovic, D.; Zickermann, V.; Wibom, R.; Hultenby, K.; et al. LRPPRC is necessary for polyadenylation and coordination of translation of mitochondrial mRNAs. EMBO J. 2011, 31, 443-456. [CrossRef] [PubMed]

44. Karasik, A.; Wilhelm, C.A.; Fierke, C.A.; Koutmos, M. Disease-associated mutations in mitochondrial precursor tRNAs affect binding, m1R9 methylation, and tRNA processing by mtRNase P. RNA 2021, 27, 420-432. [CrossRef] [PubMed]

45. Li, F.; Liu, X.; Zhou, W.; Yang, X.; Shen, Y. Auto-inhibitory Mechanism of the Human Mitochondrial RNase P Protein Complex. Sci. Rep. 2015, 5, 9878. [CrossRef] [PubMed]

46. Falk, M.J.; Gai, X.; Shigematsu, M.; Vilardo, E.; Takase, R.; McCormick, E.; Christian, T.; Place, E.; Pierce, E.; Consugar, M.; et al. A novelHSD17B10mutation impairing the activities of the mitochondrial RNase P complex causes X-linked intractable epilepsy and neurodevelopmental regression. RNA Biol. 2015, 13, 477-485. [CrossRef] 
47. Oerum, S.; Roovers, M.; Rambo, R.P.; Kopec, J.; Bailey, H.J.; Fitzpatrick, F.; Newman, J.A.; Newman, W.G.; Amberger, A.; Zschocke, J.; et al. Structural insight into the human mitochondrial tRNA purine N1-methyltransferase and ribonuclease P complexes. J. Biol. Chem. 2018, 293, 12862-12876. [CrossRef]

48. Pan, T.; Sosnick, T. RNA FOLDING DURING TRANSCRIPTION. Annu. Rev. Biophys. Biomol. Struct. 2006, 35, 161-175. [CrossRef] [PubMed]

49. Wang, G.; Chen, H.W.; Oktay, Y.; Zhang, J.; Allen, E.L.; Smith, G.M.; Fan, K.C.; Hong, J.S.; French, S.W.; McCaffery, J.M.; et al. PNPASE regulates RNA import into mitochondria. Cell 2010, 142, 456-467. [CrossRef]

50. Puranam, R.S.; Attardi, G. The RNase P Associated with HeLa Cell Mitochondria Contains an Essential RNA Component Identical in Sequence to That of the Nuclear RNase P. Mol. Cell. Biol. 2001, 21, 548-561. [CrossRef]

51. Noh, J.H.; Kim, K.M.; Abdelmohsen, K.; Yoon, J.H.; Panda, A.C.; Munk, R.; Kim, J.; Curtis, J.; Moad, C.A.; Wohler, C.M.; et al. HuR and GRSF1 modulate the nuclear export and mitochondrial localization of the lncRNA RMRP. Genes Dev. 2016, 30, 1224-1239.

52. Foriel, S.; Willems, P.; Smeitink, J.; Schenck, A.; Beyrath, J. Mitochondrial diseases: Drosophila melanogaster as a model to evaluate potential therapeutics. Int. J. Biochem. Cell Biol. 2015, 63, 60-65. [CrossRef] [PubMed]

53. Sen, A.; Cox, R.T. Fly Models of Human Diseases: Drosophila as a Model for Understanding Human Mitochondrial Mutations and Disease. Curr. Top Dev. Biol. 2017, 121, 1-27.

54. Ugur, B.; Chen, K.; Bellen, H.J. Drosophila tools and assays for the study of human diseases. Dis. Model. Mech. 2016, 9, 235-244. [CrossRef]

55. Gratz, S.J.; Cummings, A.M.; Nguyen, J.N.; Hamm, D.C.; Donohue, L.K.; Harrison, M.M.; Wildonger, J.; O’Connor-Giles, K.M. Genome Engineering of Drosophila with the CRISPR RNA-Guided Cas9 Nuclease. Genetics 2013, 194, 1029-1035. [CrossRef] [PubMed]

56. Clemente, P.; Pajak, A.; Laine, I.; Wibom, R.; Wedell, A.; Freyer, C.; Wredenberg, A. SUV3 helicase is required for correct processing of mitochondrial transcripts. Nucleic Acids Res. 2015, 43, 7398-7413. [CrossRef] [PubMed] 